Supplementary Information for

\title{
Aliphatic Ether Bond Formation Expands the Scope of Radical SAM Enzymes in Natural Product Biosynthesis
}

\author{
Kenzie A. Clark, 'Leah B. Bushin, ${ }^{\dagger}$ and Mohammad R. Seyedsayamdost ${ }^{\dagger, t, *}$ \\ Departments of Chemistry ${ }^{\dagger}$ and Molecular Biology ${ }^{\ddagger}$, Princeton University, Princeton, NJ, USA \\ *Email: mrseyed@princeton.edu
}


Materials and strains. All materials were obtained from MilliporeSigma or Fisher Scientific unless otherwise specified. Restriction enzymes, T4 DNA ligase, Q5 ${ }^{\circledR}$ HighFidelity DNA Polymerase, Q5 ${ }^{\circledR}$ Site-Directed Mutagenesis Kit, Trypsin-ultraTM Mass Spectrometry Grade, Endoproteinase GluC, Shrimp Alkaline Phosphatase (rSAP), and the corresponding buffers were purchased from New England BioLabs (NEB). All Fmocand side chain-protected amino acids, and other components for solid-phase peptide synthesis were purchased from MilliporeSigma, except for HOBt which was obtained from AnaSpec. DNA purification kits were purchased from Qiagen. The tqqB gene, codonoptimized for expression in $E$. coli, was purchased from GENEWIZ as a gene fragment in a pUC19 vector.

General procedures. UV-vis spectra were acquired on a Cary 60 UV-visible spectrophotometer (Agilent). HPLC separations were carried out on an Agilent 1260 Infinity Series analytical or preparative HPLC system equipped with a photodiode array detector and an automated fraction collector. Low resolution HPLC-MS analysis was performed on an Agilent instrument consisting of a liquid autosampler, a 1260 Infinity Series HPLC system coupled to a photodiode array detector and a 6120 Series ESI mass spectrometer. A Phenomenex ${ }^{\circledR}$ Luna C18 column $(3 \mu \mathrm{m}, 4.6 \times 100 \mathrm{~mm})$ was used with a flow rate of $0.5 \mathrm{~mL} / \mathrm{min}$ and a gradient of $5 \% \mathrm{MeCN}$ in $\mathrm{H}_{2} \mathrm{O}$ to $100 \% \mathrm{MeCN}$ over $12 \mathrm{~min}$. Both $\mathrm{MeCN}$ and $\mathrm{H}_{2} \mathrm{O}$ contained $0.1 \%(\mathrm{v} / \mathrm{v}$ ) formic acid. High-resolution (HR) HPLC-MS was carried out on an Agilent UHD Accurate Mass Q-tof LC-MS system, equipped with a 1260 Infinity Series HPLC, an automated liquid sampler, a photodiode array detector, a JetStream ESI source, and the 6540 Series Q-tof. Samples were separated on a Phenomenex ${ }^{\circledast}$ Luna C18 column $(3 \mu \mathrm{m}, 4.6 \times 100 \mathrm{~mm})$ operating at $0.5 \mathrm{~mL} / \mathrm{min}$ with a gradient of $5 \% \mathrm{MeCN}$ in $\mathrm{H}_{2} \mathrm{O}$ to $95 \% \mathrm{MeCN}$ over $13 \mathrm{~min}$ ( $+0.1 \%$ formic acid. NMR spectra were acquired at the Princeton University Department of Chemistry Facilities in $\mathrm{D}_{2} \mathrm{O}$ or $\mathrm{H}_{2} \mathrm{O} / \mathrm{D}_{2} \mathrm{O}$ (19:1) in the triple resonance cryoprobe of a Bruker A8 Avance III HD $800 \mathrm{MHz}$ NMR spectrometer or a Bruker A1 Avance III $500 \mathrm{MHz}$ NMR spectrometer. 1D/2D NMR data were analyzed with MestReNova software.

Cloning of TqqB. The tqqB gene (IMG gene ID: 2552353593, S. suis R735) was PCRamplified from a pUC19 vector using $Q 5^{\circledR}$ DNA Polymerase in FailSafe ${ }^{\mathrm{TM}}$ Buffer $\mathrm{D}$ (Epicentre) and primers tqqB_F (Ndel) and tqqB_R (BamHI) (Table S2). The PCR product was purified using the QIAquick PCR Purification Kit and subsequently digested with Ndel and BamHI. The vector pET-28b(+) was digested with the same restriction enzymes and subsequently treated with rSAP. The digested fragment and plasmid were purified using the QIAquick Gel Extraction Kit and ligated in an insert:vector molar ratio of 5:1 using T4 DNA Ligase. The reaction was incubated for 3 hours at room temperature, heat inactivated for $10 \mathrm{~min}$ at $65^{\circ} \mathrm{C}$, and transformed into chemically-competent $E$. coi $\mathrm{DH} 5 \alpha$ cells. The transformants were selected on an LB agar plate containing kanamycin (50 
$\mu \mathrm{g} / \mathrm{mL})$. The target vector $\mathrm{pET}-28 \mathrm{~b}(+)$ _tqqB was isolated from a liquid culture of a single colony using the QIAprep Spin Miniprep Kit. Insertion of the gene fragment was confirmed by sequencing with the T7 promoter and terminator primers. Vectors $\mathrm{pET}-28 \mathrm{~b}(+)$ _t $q q B$ and pDB1282, which carries the isc operon required for proper assembly of the Fe-S clusters in TqqB, were subsequently co-transformed into chemically-competent $E$. coli BL21(DE3) cells for expression.

Mutagenesis of TqqB. Mutagenesis of the active-site [4Fe-4S] cluster and the putative auxiliary cluster was carried out on vector pET-28b(+)_tqqB using the $Q 5^{\circledR}$ Site-Directed Mutagenesis Kit. Two cysteine-to-alanine mutations were made in a single mutagenesis step for each cluster. Sites of mutation were selected based on the sequence alignment to SuiB (Figure S2). Primers (Table S2) were designed using the NEBaseChanger software. The standard protocol was followed with some modifications; a gel extraction step was included to isolate the correct plasmid band after the PCR step and the KLD reaction was incubated at room temperature for 3 hours rather than 15 min before transformation. Single colonies were selected for sequencing and plasmids with the correct double mutations were subsequently co-transformed with pDB1282 into chemically-competent $E$. coli BL21(DE3) cells for expression.

Expression, Purification, and Reconstitution of TqqB and Mutants. Expression, purification, and reconstitution of TqqB and TqqB mutants were carried out using previously published procedures without modifications. ${ }^{1}$ Concentrations of purified TqqB and mutants were quantified using the method reported by Barr et al. ${ }^{2}$ Purified TqqB and mutant enzymes were anaerobically reconstituted with 10 -fold excess $\mathrm{Fe}^{2+}$ and $\mathrm{S}^{2-}$ as previously reported. ${ }^{1}$

Synthesis of Substrate (TqqA) and Substrate Variants by SPPS. The $37 \mathrm{mer}$ TqqA was synthesized via Fmoc-based solid phase chemistry using an automated microwave peptide synthesizer (CEM). Preloaded HMPB-Tyr(OtBu)-ChemMatrix ${ }^{\circledR}$ resin $(0.1 \mathrm{mmol})$ and standard Fmoc and side chain-protected amino acids were used. The resin was swelled in DMF $(10 \mathrm{~mL})$ for 3 minutes. Fmoc deprotection reactions were performed using $10 \%$ piperazine $(\mathrm{w} / \mathrm{v})$ in a $10: 90$ solution of EtOH:NMP $(3 \mathrm{~mL})$ with $0.1 \mathrm{M} \mathrm{HOBt}$. Fmocamino acids were coupled using $0.5 \mathrm{M}$ DIC in DMF as an activating reagent. The resin was washed 3 times with a total volume of $7 \mathrm{~mL}$ DMF following deprotection. Amino acids 2-17 were coupled with a single coupling reaction for 4 minutes at $75^{\circ} \mathrm{C}$. with 5 equiv. of each amino acid. Amino acids 18-37 were double coupled with two successive 4 min coupling reactions at $75{ }^{\circ} \mathrm{C}$ with 5 equiv. of each amino acid. The terminal Fmoc group was deprotected in the last step of the synthesis. Upon completion of the synthesis, the resin was removed from the reaction vessel of the peptide synthesizer and transferred to an Econo-Pac column (BioRad). The resin was washed several times with DMF, followed 
by DCM, then dried thoroughly under vacuum. The peptide was cleaved from the resin by incubation with freshly-prepared cleavage cocktail $(5 \mathrm{~mL})$ consisting of $92.5 \%$ TFA, $2.5 \% \mathrm{H} 2 \mathrm{O}, 2.5 \% \mathrm{TIS}$, and $2.5 \%$ DODT, which was added to prevent oxidation of Met. The reaction was stirred for $3 \mathrm{~h}$ at room temperature. The mixture was drained from the reaction tube and the resin was rinsed several times with TFA. The filtrate and rinses were combined and subsequently concentrated by evaporation of TFA under a stream of $\mathrm{N}_{2}$. The peptide was precipitated by addition of 10 volumes of ice-cold diethyl ether. The ether/peptide suspension was incubated at $-20^{\circ} \mathrm{C}$ for 20 minutes before isolating the precipitated peptide by centrifugation $\left(4^{\circ} \mathrm{C}, 3500 \mathrm{~g}, 15 \mathrm{~min}\right)$. The ether was poured off and the peptide was dried overnight.

Purification of TqqA and Variants. Crude TqqA was dissolved in $40 \% \mathrm{MeCN}(+0.1 \%$ formic acid) and purified by preparative HPLC. Repeated injections were performed on a preparative Phenomenex ${ }^{\circledR}$ Luna C18 column $(5 \mu \mathrm{m}, 250 \times 21.20 \mathrm{mmm})$, which was equilibrated in $15 \% \mathrm{MeCN}$ in $\mathrm{H}_{2} \mathrm{O}(+0.1 \%$ formic acid). The peptide was eluted with a gradient of $8-58 \% \mathrm{MeCN}$ over 18 minutes to give pure TqqA, which was verified by HRHPLC-MS (Table S4).

Enzymatic Activity Assays. Enzymatic assays were performed in an inert atmosphere in a glovebox (MBraun). The TqqA peptide substrate was brought into the glovebox as aliquots of lyophilized powder for the appropriate reaction volume. Reactions were typically carried out in $1.5 \mathrm{~mL}$ Eppendorf tubes on a $30 \mu \mathrm{L}$ scale and contained assay buffer (100 mM HEPES, $300 \mathrm{mM} \mathrm{KCl,} \mathrm{10 \%} \mathrm{glycerol,} \mathrm{pH} 7.5$ ), $30 \mu \mathrm{M}$ TqqB, $5 \mathrm{mM}$ sodium dithionite (DT), $5 \mathrm{mM}$ dithiothreitol (DTT), $1 \mathrm{mM}$ SAM and $500 \mu \mathrm{M}$ TqqA. After 5 hours of incubation, reactions were removed from the glovebox and quenched by addition of an equal volume of $\mathrm{MeCN}(+1 \%$ formic acid). Precipitated protein was removed by centrifugation. Samples were then analyzed by HR-HPLC-MS as described above. Substrate and product typically eluted in a single peak at $40 \% \mathrm{MeCN}$. Relative quantification of product formation was conducted by analysis of extracted ion chromatograms.

Proteolytic Digestion of Reaction Product. To analyze the proteolysis fragments of the TqqA substrate and product, $100 \mu \mathrm{L}-5 \mathrm{~mL}$ reactions were set up and quenched as described above. For digestion by trypsin, $\mathrm{CaCl}_{2}$ was added to the sample from a $2 \mathrm{M}$ stock to achieve a final concentration of $20 \mathrm{mM}$. Trypsin-ultra ${ }^{\mathrm{TM}}$ Mass Spectrometry Grade was added to a final concentration of 100:1 substrate to trypsin. Reactions were incubated for 24 hours at $37^{\circ} \mathrm{C}$. For digestion by GluC, an equal volume of $2 x$ GluC Reaction Buffer ( $50 \mathrm{mM}$ Tris-HCl, $0.5 \mathrm{mM}$ Glu-Glu, pH 8) was added to the supernatant to a final concentration of 50:1 substrate to enzyme. Reactions were incubated for 24 hours at $37^{\circ} \mathrm{C}$. Proteolysis reactions were directly analyzed by HPLC-Qtof-MS as 
described above. In certain cases, reactions were first desalted using a Pierce ${ }^{\mathrm{TM}}$ graphite spin columns prior to MS analysis.

Large Scale Assays and Proteolysis of Product. Large-scale reactions to generate enough product for NMR analysis were carried out on a $5 \mathrm{~mL}$ scale with the same assay components and concentrations as described above. Reactions were allowed to incubate for 5 hours and then brought out the glovebox, quenched, and digested with trypsin as described above.

Isolation of Product Fragment. The 5mer product fragment (TQQTK) from the trypsin digestion was isolated by HPLC. Repeated injections were performed on a semipreparative Phenomenex ${ }^{\circledR}$ Luna C18 $100 \AA$ column $(5 \mu \mathrm{m}, 250 \times 10 \mathrm{~mm})$, which was equilibrated in $5 \% \mathrm{MeCN}$ in $\mathrm{H}_{2} \mathrm{O}(+0.1 \%$ formic acid). The peptide was eluted with a gradient of $5-49 \% \mathrm{MeCN}$ over 20 minutes at a flow rate of $2.5 \mathrm{~mL} / \mathrm{min}$. Fractions were collected at 0.1 min intervals during the first 10 minutes. Each fraction was tested by HPLC-MS and fractions containing the expected product 5 mer fragment were pooled and dried by lyophilization. The lyophilized material was resuspended in $\mathrm{H}_{2} \mathrm{O}(+0.1 \%$ formic acid) and repeated injections were performed on an analytical Phenomenex ${ }^{\circledR}$ Synergi ${ }^{\mathrm{TM}}$ Fusion-RP $80 \AA$ column $(4 \mu \mathrm{m}, 100 \times 4.6 \mathrm{~mm})$, which was equilibrated with $100 \% \mathrm{H}_{2} \mathrm{O}$ $(+0.1 \%$ formic acid). The peptide was eluted with a gradient of $0-20 \% \mathrm{MeCN}$ over 5 minutes at a flow rate of $0.5 \mathrm{~mL} / \mathrm{min}$. Fractions containing the pure product were pooled and lyophilized.

Enzymatic Activity Assays with TqqA Variants. Enzymatic assays for TqqA substrate variants were performed as described above but were incubated overnight. The peptides were then digested with the GluC protease as described above; subsequently HR-MS and HR-MS/MS analysis was carried out on the 17 mer fragment. For quantification of conversion yield relative to wt TqqA, reactions were quenched with and equal volume of $\mathrm{MeCN}(+1 \%$ formic acid) and analyzed by HR-HPLC-MS. For each variant, the extracted ion chromatogram of the three most abundant charge states for the substrate and product was integrated and the product/substrate ratio determined relative to the ratio obtained for the wt TqqA reaction (see Figure 5 and Table S7). Yields reported are based on quantification of the most abundant charge state, though very similar values $( \pm 10 \%$ of the reported yield) were obtained from quantification of other charge states. 
Table S1. Strains and plasmids used and generated in this study.

\begin{tabular}{|c|c|c|}
\hline Strain/Plasmid & Purpose & Source \\
\hline E. coli DH5 $\alpha$ & Host strain for cloning & NEB \\
\hline E. coli BL21(DE3) & Host strain for expression & NEB \\
\hline pET-28b(+) & Kan $^{R}$, Expression vector & Novagen \\
\hline pDB1282 & isc operon & $\begin{array}{l}\text { Prof. Dennis Dean \& } \\
\text { Prof. Squire Booker }\end{array}$ \\
\hline pET-28b(+)_tqqB & $\begin{array}{c}\text { Kan }^{R} \text {, Expression of TqqB } \\
\text { WT }\end{array}$ & This study \\
\hline $\begin{array}{l}\text { E. coli BL21(DE3) + pET- } \\
28 \mathrm{~b}(+) \_t q q B+p D B 1282\end{array}$ & Expression of TqqB WT & This study \\
\hline $\begin{array}{c}\mathrm{pET}- \\
28 \mathrm{~b}(+) \_t q q B \_C 335 \mathrm{~A} / \mathrm{C} 353 \mathrm{~A}\end{array}$ & $\begin{array}{c}\mathrm{Kan}^{\mathrm{R}} \text {, Expression of TqqB } \\
\text { C335A/C353A }\end{array}$ & This study \\
\hline 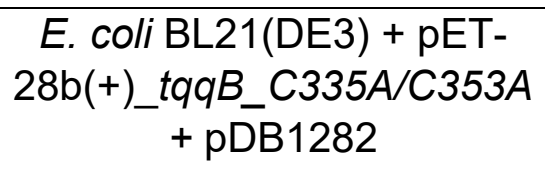 & $\begin{array}{l}\text { Expression of TqqB } \\
\text { C335A/C353A }\end{array}$ & This study \\
\hline $\begin{array}{c}\mathrm{pET}- \\
28 \mathrm{~b}(+) \_t q q B \_C 112 A / C 119 A\end{array}$ & $\begin{array}{c}\text { Kan }^{R} \text {, Expression of TqqB } \\
\text { C112A/C119A }\end{array}$ & This study \\
\hline $\begin{array}{c}\text { E. coli BL21(DE3) + pET- } \\
28 \mathrm{~b}(+) \_t q q B \_C 112 A / C 119 A \\
+ \text { pDB1282 }\end{array}$ & $\begin{array}{l}\text { Expression of TqqB } \\
\text { C112A/C119A }\end{array}$ & This study \\
\hline
\end{tabular}


Table S2. Primers used in this study.

\begin{tabular}{|l|l|}
\hline tqqB_F (Ndel) & TCCTGGCATATGAAGTTCATGCTGAATTGTGAC \\
\hline tqqB_R (BamHI) & TCGATTGGATCCTTATTTTTTCTCAACCATTTTGTAAATT \\
TCC \\
\hline $\begin{array}{l}\text { tqqB_C335A/C353 } \\
\text { A_F }\end{array}$ & CAACGAGAGCGGCCATATCAAACCGGCCACCTTTTTTC \\
CGGACGGC \\
\hline tqqB_C335A/C353 & $\begin{array}{l}\text { ATGGTCCATTCGATAACACCGGCGCCAGCGCGCATGGT } \\
\text { GCCATCAAC }\end{array}$ \\
\hline $\begin{array}{l}\text { tqqB_C112A/C119 } \\
\text { A_F }\end{array}$ & TGTACCCATGCCTTCAAAGAAGCTGGTCCG \\
\hline $\begin{array}{l}\text { tqqB_C112A/C119 } \\
\text { A_R }\end{array}$ & CTGTAAATGGGCCTTGTTGGTCAGTTCAATAAC \\
\hline
\end{tabular}

Table S3. Iron and labile sulfide quantification for wt and mutant TqqB after the reconstitution reaction. Shown are the averages of three independent measurements with the standard deviation (S.D.) noted in parentheses.

\begin{tabular}{|c|c|c|}
\hline Protein & Fe/protomer (S.D.) & S $^{2-/}$ protomer (S.D.) \\
\hline TqqB WT & $8.66(0.01)$ & $8.49(0.29)$ \\
\hline TqqB C112A/C119A & $4.69(0.04)$ & $4.91(0.34)$ \\
\hline TqqB C335A/C353A & $4.44(0.06)$ & $3.90(0.31)$ \\
\hline
\end{tabular}


Table S4. Substrate and product HR-MS data before and after protease digestion.

\begin{tabular}{|c|c|c|c|c|}
\hline \multicolumn{2}{|c|}{ Fragment } & Calc m/z & Obs m/z & $\Delta$ ppm \\
\hline \multicolumn{2}{|c|}{$\begin{array}{c}\text { MSVIEFKKLSSKLLKVSKIETLSGCGTKRT } \\
\text { QQTKGWY } \\
\text { (Substrate) }\end{array}$} & $\begin{array}{c}{[\mathrm{M}+3 \mathrm{H}]^{3+}: 1401.77259} \\
{[\mathrm{M}+4 \mathrm{H}]^{4+}: 1051.58126} \\
{[\mathrm{M}+5 \mathrm{H}]^{5+}: 841.46646} \\
{[\mathrm{M}+6 \mathrm{H}]^{6+:}: 701.38993} \\
{[\mathrm{M}+7 \mathrm{H}]^{7+}: 601.33527}\end{array}$ & $\begin{array}{l}1401.78407 \\
1051.59087 \\
841.47257 \\
701.39630 \\
601.34053\end{array}$ & $\begin{array}{l}8.2 \\
9.1 \\
7.3 \\
9.1 \\
8.8\end{array}$ \\
\hline \multicolumn{2}{|c|}{$\begin{array}{c}\text { MSVIEFKKLSSKLLKVSKIETLSGCGTKRT } \\
\text { QQTKGWY } \\
\text { (Product) }\end{array}$} & $\begin{array}{c}{[\mathrm{M}+4 \mathrm{H}]^{4+}: 1051.07735} \\
{[\mathrm{M}+5 \mathrm{H}]^{5+}: 841.06333} \\
{[\mathrm{M}+6 \mathrm{H}]^{6+:}: 701.05399} \\
{[\mathrm{M}+7 \mathrm{H}]^{7+}: 601.04732}\end{array}$ & $\begin{array}{l}1051.08558 \\
841.06975 \\
701.05912 \\
601.05222\end{array}$ & $\begin{array}{l}7.8 \\
7.6 \\
7.3 \\
8.2\end{array}$ \\
\hline \multirow{4}{*}{$\begin{array}{c}\text { GluC } \\
\text { Digestion }\end{array}$} & MSVIE & $\begin{array}{c}{[\mathrm{M}+\mathrm{H}]^{1+:}: 578.28543} \\
{[\mathrm{M}+2 \mathrm{H}]^{2+}: 289.64635}\end{array}$ & $\begin{array}{l}578.28829 \\
289.64453\end{array}$ & $\begin{array}{l}5.0 \\
6.3\end{array}$ \\
\hline & FKKLSSKLLKVSKIE & $\begin{array}{l}{[\mathrm{M}+2 \mathrm{H}]^{2+}: 874.55585} \\
{[\mathrm{M}+3 \mathrm{H}]^{3+}: 583.37299}\end{array}$ & $\begin{array}{l}874.55650 \\
583.37717\end{array}$ & $\begin{array}{l}0.7 \\
7.2\end{array}$ \\
\hline & $\begin{array}{c}\text { TLSGCGTKRTQQTKGWY } \\
\text { (Substrate) }\end{array}$ & $\begin{array}{l}{[\mathrm{M}+2 \mathrm{H}]^{2+}: 957.97817} \\
{[\mathrm{M}+3 \mathrm{H}]^{3+}: 638.98787} \\
{[\mathrm{M}+4 \mathrm{H}]^{4+}: 479.49272}\end{array}$ & $\begin{array}{l}957.97230 \\
638.98704 \\
479.49519\end{array}$ & $\begin{array}{l}6.1 \\
1.3 \\
5.2\end{array}$ \\
\hline & $\begin{array}{c}\text { TLSGCGTKRTQQTKGWY } \\
\text { (Product) }\end{array}$ & $\begin{array}{l}{[\mathrm{M}+2 \mathrm{H}]^{2+}: 956.97035} \\
{[\mathrm{M}+3 \mathrm{H}]^{3+}: 638.31595}\end{array}$ & $\begin{array}{l}956.97008 \\
638.31599\end{array}$ & $\begin{array}{l}0.3 \\
4.3\end{array}$ \\
\hline \multirow{7}{*}{$\begin{array}{l}\text { Trypsin } \\
\text { Digestion }\end{array}$} & MSVIEFK & {$[\mathrm{M}+\mathrm{H}]^{1+}: 853.44880$} & 853.45014 & 1.6 \\
\hline & LSSK & {$[\mathrm{M}+\mathrm{H}]^{1+}: 434.26092$} & 434.26501 & 9.4 \\
\hline & $\begin{array}{l}\text { LLK } \\
\text { VSK }\end{array}$ & $\begin{array}{l}{[\mathrm{M}+\mathrm{H}]^{+1}: 373.28093} \\
{[\mathrm{M}+\mathrm{H}]^{1+}: 333.21325}\end{array}$ & $\begin{array}{l}373.28367 \\
333.21376\end{array}$ & $\begin{array}{l}7.3 \\
1.5\end{array}$ \\
\hline & IETLSGCGTK & {$[\mathrm{M}+\mathrm{H}]^{1+:}: 1008.50302$} & 1008.49776 & 5.2 \\
\hline & $\begin{array}{c}\text { TQQTK } \\
\text { (Substrate) }\end{array}$ & $\begin{array}{c}{[\mathrm{M}+\mathrm{H}]^{1+}: 605.32532} \\
{[\mathrm{M}+2 \mathrm{H}]^{2+}: 303.16634}\end{array}$ & $\begin{array}{l}605.32393 \\
303.16447\end{array}$ & $\begin{array}{l}2.3 \\
6.2\end{array}$ \\
\hline & $\begin{array}{l}\text { TQQTK } \\
\text { (Product) }\end{array}$ & $\begin{array}{c}{[\mathrm{M}+\mathrm{H}]^{1+}: 603.30967} \\
{[\mathrm{M}+\mathrm{H}]^{2+}: 302.158515}\end{array}$ & $\begin{array}{l}603.31166 \\
302.15559\end{array}$ & $\begin{array}{l}3.3 \\
9.7\end{array}$ \\
\hline & GWY & {$[\mathrm{M}+\mathrm{H}]^{1+}: 425.18195$} & 425.18582 & 9.1 \\
\hline
\end{tabular}


Table S5. Complete NMR assignments (from spectra obtained in $\mathrm{D}_{2} \mathrm{O}$ ) for the synthetic $5 \mathrm{mer}$ substrate and the $5 \mathrm{mer}$ derived from the trypsin-cut product of the TqqB reaction. Carbonyl signals for all but residues Q31 and Q32 were not observed in the HMBC spectrum.

\begin{tabular}{|c|c|c|c|c|c|}
\hline \multicolumn{2}{|c|}{$\mathrm{TqqA}_{30-34}$} & \multicolumn{2}{|c|}{ Substrate } & \multicolumn{2}{|c|}{ Product } \\
\hline \multirow{4}{*}{ T30 } & C & $\begin{array}{c}\delta \mathrm{H} \\
-\end{array}$ & $\begin{array}{c}\delta C \\
167.96\end{array}$ & $\begin{array}{c}\delta \mathrm{H} \\
-\end{array}$ & $\begin{array}{c}\mathrm{\delta C} \\
\text { Not Obs }\end{array}$ \\
\hline & $\alpha$ & 3.80 & 58.40 & 3.42 & 63.86 \\
\hline & $\beta$ & 4.06 & 66.15 & 4.09 & 64.94 \\
\hline & $\mathrm{Y1}$ & 1.21 & 18.70 & 1.14 & 19.26 \\
\hline \multirow{5}{*}{ Q31* } & C & - & 172.77 & - & 173.79 \\
\hline & $\alpha$ & 4.32 & 53.09 & - & 77.76 \\
\hline & $\beta$ & $2.01,1.91$ & 26.73 & 2.08 & 31.93 \\
\hline & $\mathrm{V}$ & 2.28 & 30.84 & 2.27 & 28.60 \\
\hline & $\mathrm{C \delta}$ & - & 177.70 & - & 177.76 \\
\hline \multirow{5}{*}{ Q32* } & C & - & 172.77 & - & Not Obs. \\
\hline & $\alpha$ & 4.32 & 53.09 & 4.29 & 53.44 \\
\hline & $\beta$ & $2.01,1.91$ & 26.73 & $2.01,1.93$ & 26.54 \\
\hline & $\mathrm{V}$ & 2.28 & 30.84 & 2.26 & 31.16 \\
\hline & Cठ & - & 177.70 & - & 177.50 \\
\hline \multirow{4}{*}{ T33 } & $C$ & - & 170.79 & - & Not Obs. \\
\hline & $\alpha$ & 4.24 & 59.08 & 4.19 & 59.12 \\
\hline & $\beta$ & 4.12 & 67.08 & 4.07 & 67.14 \\
\hline & $\mathrm{Y1}$ & 1.11 & 18.79 & 1.05 & 18.80 \\
\hline \multirow{6}{*}{ K34 } & C & - & 178.08 & - & Not Obs. \\
\hline & $\alpha$ & 4.09 & 54.81 & 4.03 & 55.09 \\
\hline & $\beta$ & $1.73,1.63$ & 30.85 & $1.69,1.59$ & 31.01 \\
\hline & $\mathrm{Y}$ & 1.29 & 21.86 & 1.24 & 22.01 \\
\hline & $\delta$ & 1.57 & 26.25 & 1.54 & 26.33 \\
\hline & $\varepsilon$ & 2.88 & 39.08 & 2.84 & 39.26 \\
\hline
\end{tabular}

* Substrate glutamine signals are interchangeable 
Table S6. Complete NMR assignments (from spectra obtained in $95: 5 \mathrm{H}_{2} \mathrm{O}_{/} \mathrm{D}_{2} \mathrm{O}$ ) for the synthetic $5 \mathrm{mer}$ substrate and the $5 \mathrm{mer}$ derived from the trypsin-cut product of the TqqB reaction. An HMBC spectrum was not obtained so no shifts were assigned for quaternary carbons. Only TOCSY and ROESY spectra were recorded for the 5 mer substrate.

\begin{tabular}{|c|c|c|c|c|}
\hline \multirow{2}{*}{\multicolumn{2}{|c|}{$\mathrm{TqqA}_{30-34}$}} & \multirow{3}{*}{$\begin{array}{c}\text { Substrate } \\
\mathrm{\delta H} \\
\text { Not Obs. }\end{array}$} & \multicolumn{2}{|c|}{ Product } \\
\hline & & & $\delta \mathrm{H}$ & $\delta C$ \\
\hline \multirow{4}{*}{ T30 } & $\mathrm{N}$ & & Not Obs. & - \\
\hline & $\alpha$ & 3.78 & 3.45 & 64.48 \\
\hline & $\beta$ & 4.05 & 4.15 & 65.15 \\
\hline & y1 & 1.22 & 1.18 & 19.43 \\
\hline \multirow{5}{*}{ Q31 } & $\mathrm{N}$ & 8.94 & 8.91 & - \\
\hline & $\alpha$ & 4.32 & - & Not Obs. \\
\hline & $\beta$ & $1.91,1.57$ & 2.11 & 31.95 \\
\hline & Y & 2.28 & 2.31 & 28.71 \\
\hline & $\mathrm{N}$ & $6.91,7.59$ & $6.86,7.62$ & - \\
\hline \multirow{5}{*}{ Q32 } & $\mathrm{N}$ & 8.72 & 8.67 & - \\
\hline & $\alpha$ & 4.32 & 4.32 & 53.45 \\
\hline & $\beta$ & $2.01,1.91$ & $2.04,1.97$ & 26.41 \\
\hline & Y & 2.28 & 2.28 & 31.02 \\
\hline & $\mathrm{N}$ & $6.91,7.59$ & $6.86,7.62$ & - \\
\hline \multirow{4}{*}{ T33 } & $\mathrm{N}$ & 8.40 & 8.40 & - \\
\hline & $\alpha$ & 4.24 & 4.21 & 59.37 \\
\hline & $\beta$ & 4.13 & 4.10 & 67.14 \\
\hline & y1 & 1.11 & 1.08 & 18.80 \\
\hline \multirow{7}{*}{ K34 } & $\mathrm{N}$ & 8.12 & 8.12 & - \\
\hline & $\alpha$ & 4.07 & 4.06 & 55.09 \\
\hline & $\beta$ & $1.63,1.71$ & $1.62,1.71$ & 30.96 \\
\hline & Y & 1.30 & 1.27 & 21.95 \\
\hline & $\delta$ & 1.57 & 1.57 & 26.44 \\
\hline & $\varepsilon$ & 2.88 & 2.88 & 39.49 \\
\hline & $\mathrm{N}$ & 7.50 & Not Obs. & Not Obs. \\
\hline
\end{tabular}


Table S7. HR-MS data for the products of the TqqB reaction with T30 and Q31 variants. The average conversion yields ( \pm S.D.) of three independent measurements are shown using the dominant charge state. In addition, the percent conversion was determined from the next two most abundant charge states and was found to be within $10 \%$ of the reported values below.

\begin{tabular}{|c|c|c|c|c|}
\hline Peptide & $\begin{array}{c}{[\mathbf{M + 5 H}]^{5+}: \text { Calc m/z }} \\
-\mathbf{2 H} \text { (Product) }\end{array}$ & {$[\mathbf{M + 5 H}]^{5+}:$ Obs m/z } & $\Delta \mathbf{p p m}$ & $\begin{array}{c}\text { \% Conversion } \\
\text { Relative to WT }\end{array}$ \\
\hline Q31D & 838.45701 & 838.47229 & 18.2 & $35 \pm 1$ \\
\hline Q31E & 841.26014 & 841.26705 & 8.2 & $73 \pm 1$ \\
\hline Q31N & 838.26020 & 838.27214 & 14.2 & $81 \pm 6$ \\
\hline Q31A & 829.65904 & 829.67362 & 17.6 & $101 \pm 8$ \\
\hline Q31G & 826.85591 & 826.86856 & 15.3 & $66 \pm 4$ \\
\hline T30S & 838.26020 & 838.27569 & 18.5 & $16 \pm 1$ \\
\hline T30C & 841.85877 & $n / a$ & $n / a$ & 0 \\
\hline Q31N-Me-Q & 843.86646 & 843.86180 & 5.5 & $97 \pm 10$ \\
\hline
\end{tabular}

Table S8. HR-MS/MS data for the products of the TqqB reaction with wt TqqA as well as T30 and Q31 variants after GluC treatment.

\section{A. WT TqqA}

\begin{tabular}{|c|c|c|c|c|}
\hline Ion & Calc $\mathrm{m} / \mathrm{z}$ & Obs $\mathrm{m} / \mathrm{z}$ & $\Delta \mathrm{ppm}$ & Sequence \\
\hline $\mathbf{b}_{2}{ }^{+1}$ & 215.13906 & 215.12682 & 56.9 & TL \\
\hline $\mathbf{b}_{3}{ }^{+1}$ & 302.17109 & 302.17256 & 4.9 & TLS \\
\hline$b_{9}{ }^{+1}$ & 904.46696 & 904.46314 & 4.2 & TLSGCGTKR \\
\hline$b_{11}{ }^{+1}-2 H$ & 1131.55756 & 1131.55502 & 2.2 & TLSGCGTKRTQ \\
\hline $\mathbf{b}_{14}{ }^{+2}-2 \mathrm{H}$ & 744.883055 & 744.88018 & 3.9 & TLSGCGTKRTQQTK \\
\hline $\mathbf{b}_{15}{ }^{+2}-2 \mathrm{H}$ & 773.393785 & 773.38697 & 8.8 & TLSGCGTKRTQQTKG \\
\hline$b_{16}{ }^{+2}-2 H$ & 866.433435 & 866.43014 & 3.8 & TLSGCGTKRTQQTKGW \\
\hline $\mathbf{b}_{17}{ }^{+2}-2 \mathrm{H}$ & 947.965105 & 947.96209 & 3.2 & TLSGCGTKRTQQTKGWY \\
\hline$y_{1}^{+1}$ & 182.08121 & 182.0621 & 105 & $\mathrm{Y}$ \\
\hline $\mathrm{y}_{2}^{+1}$ & 368.16053 & 368.15775 & 7.6 & WY \\
\hline$y_{4}^{+1}$ & 553.27695 & 553.27767 & 1.3 & KGWY \\
\hline$y_{5}^{+1}$ & 654.32463 & 654.32756 & 4.5 & TKGWY \\
\hline
\end{tabular}




\begin{tabular}{|c|c|c|c|r|}
\hline $\mathbf{y}_{6}{ }^{+1}$ & 782.38321 & 782.38531 & 2.7 & QTKGWY \\
\hline $\mathbf{y}_{15}{ }^{+2} \mathbf{- 2 H}$ & 849.904515 & 849.89962 & 5.8 & SGCGTKRTQQTKGWY \\
\hline
\end{tabular}

B. Q31D-TqqA

\begin{tabular}{|c|c|c|c|c|}
\hline Ion & Calc $\mathbf{~ m} / \mathbf{z}$ & Obs $\mathbf{~ m} / \mathbf{z}$ & $\Delta \mathbf{p p m}$ & \multicolumn{2}{|c|}{ Sequence } \\
\hline $\mathbf{b}_{\mathbf{2}}{ }^{+1}$ & 215.13906 & 215.12687 & 56.7 & TL \\
\hline $\mathbf{b}_{\mathbf{1}}{ }^{+2} \mathbf{- 2} \mathbf{H}$ & 941.449285 & 941.45138 & 2.2 & TLSGCGTKRTEQTKGWY \\
\hline $\mathbf{y}_{1}{ }^{+1}$ & 182.08121 & 182.06295 & 100.3 & $\mathrm{Y}$ \\
\hline $\mathbf{y}_{2}{ }^{+1}$ & 368.16053 & 368.16167 & 3.1 & WY \\
\hline $\mathbf{y}_{\mathbf{4}}{ }^{+1}$ & 553.27695 & 553.28205 & 9.2 & KGWY \\
\hline
\end{tabular}

C. Q31E-TqqA

\begin{tabular}{|c|c|c|c|c|}
\hline Ion & Calc $\mathrm{m} / \mathrm{z}$ & Obs $\mathrm{m} / \mathrm{z}$ & $\Delta \mathrm{ppm}$ & Sequence \\
\hline $\mathbf{b}_{2}{ }^{+1}$ & 215.13906 & 215.12738 & 54.3 & $\mathrm{TL}$ \\
\hline$b_{3}{ }^{+1}$ & 302.17109 & 302.16833 & 9.13 & TLS \\
\hline $\mathbf{b}_{9}{ }^{+1}$ & 904.46696 & 904.46461 & 2.6 & TLSGCGTKR \\
\hline $\mathrm{b}_{14}{ }^{+2}-\mathbf{2 H}$ & 745.375055 & 745.37436 & 1.0 & TLSGCGTKRTEQTK \\
\hline$b_{15}{ }^{+2}-2 H$ & 773.885785 & 773.88648 & 0.9 & TLSGCGTKRTEQTKG \\
\hline$b_{16}{ }^{+2}-2 \mathrm{H}$ & 866.925445 & 866.92506 & 0.4 & TLSGCGTKRTEQTKGW \\
\hline$b_{17}{ }^{+2}-2 H$ & 948.457115 & 948.45702 & 0.1 & TLSGCGTKRTEQTKGWY \\
\hline$y_{1}+1$ & 182.08121 & 182.0639 & 95.1 & $\mathrm{Y}$ \\
\hline$y_{2}{ }^{+1}$ & 368.16053 & 368.16211 & 4.3 & WY \\
\hline$y_{4}^{+1}$ & 553.27695 & 553.27930 & 4.3 & KGWY \\
\hline$y_{5}{ }^{+1}$ & 654.32463 & 654.32616 & 2.3 & TKGWY \\
\hline$y_{14}{ }^{+2}-2 H$ & 806.880505 & 806.88034 & 0.2 & GCGTKRTEQTKGWY \\
\hline $\mathrm{y}_{15^{2}}{ }^{2}-2 \mathrm{H}$ & 850.396525 & 850.39676 & 0.3 & SGCGTKRTEQTKGWY \\
\hline$y_{16}{ }^{+2}-2 H$ & 906.938555 & 906.94951 & 12.1 & LSGCGTKRTEQTKGWY \\
\hline
\end{tabular}


D. Q31N-TqqA

\begin{tabular}{|c|c|c|c|c|}
\hline Ion & Calc m/z & Obs $\mathrm{m} / \mathrm{z}$ & $\Delta$ ppm & Sequence \\
\hline $\mathbf{b}_{2}^{+1}$ & 215.13906 & 215.12737 & 54.3 & $\mathrm{TL}$ \\
\hline$b_{3}{ }^{+1}$ & 302.17109 & 302.16959 & 5.0 & TLS \\
\hline $\mathrm{b}_{11}{ }^{+1}-2 \mathrm{H}$ & 1117.54191 & 1117.5327 & 8.2 & TLSGCGTKRTN \\
\hline $\mathbf{b}_{14}{ }^{+2}-2 \mathrm{H}$ & 737.875225 & 737.87481 & 0.6 & TLSGCGTKRTNQTK \\
\hline$b_{15}{ }^{+2}-2 H$ & 766.385955 & 766.38303 & 3.8 & TLSGCGTKRTNQTKG \\
\hline $\mathbf{b}_{16}{ }^{+2}-2 \mathrm{H}$ & 859.425615 & 859.42222 & 4.0 & TLSGCGTKRTNQTKGW \\
\hline $\mathbf{b}_{17^{2}}{ }^{2}-2 \mathrm{H}$ & 940.957275 & 940.94929 & 8.5 & TLSGCGTKRTNQTKGWY \\
\hline$y_{1}^{+1}$ & 182.08121 & 182.06328 & 98.4 & $\bar{Y}$ \\
\hline$y_{2}^{+1}$ & 368.16053 & 368.16304 & 6.8 & WY \\
\hline$y_{4}^{+1}$ & 553.27695 & 553.27831 & 2.5 & KGWY \\
\hline$y_{6}+1$ & 782.38321 & 782.38059 & 3.4 & QTKGWY \\
\hline $\mathrm{y}_{14^{2}}-2 \mathrm{H}$ & 799.380675 & 799.38042 & 0.3 & GCGTKRTNQTKGWY \\
\hline $\mathrm{y}_{15}{ }^{+2}-2 \mathrm{H}$ & 842.896685 & 842.89502 & 2.0 & SGCGTKRTNQTKGWY \\
\hline$y_{16}+2-2 H$ & 899.438725 & 899.45937 & 23.0 & LSGCGTKRTNQTKGWY \\
\hline
\end{tabular}

E. Q31A-TqqA

\begin{tabular}{|c|c|c|c|c|}
\hline Ion & Calc m/z & Obs $\mathrm{m} / \mathrm{z}$ & $\Delta$ ppm & Sequence \\
\hline$b_{2}{ }^{+1}$ & 215.13906 & 215.127 & 56.1 & $T L$ \\
\hline$b_{9}+1$ & 904.46696 & 904.46530 & 1.8 & TLSGCGTKR \\
\hline$b_{12}{ }^{+1}-2 H$ & 1202.59466 & 1202.58752 & 5.9 & TLSGCGTKRTAQ \\
\hline $\mathbf{b}_{14}{ }^{+1}-2 \mathrm{H}$ & 1431.73732 & 1431.7232 & 9.9 & TLSGCGTKRTAQTK \\
\hline$b_{15}{ }^{+2}-2 H$ & 744.883055 & 744.88183 & 1.6 & TLSGCGTKRTAQTKG \\
\hline$b_{16}{ }^{+2}-2 H$ & 837.922705 & 837.91313 & 11. & TLSGCGTKRTAQTKGW \\
\hline $\mathbf{b}_{17}+2-2 \mathrm{H}$ & 919.454375 & 919.44982 & 5.0 & TLSGCGTKRTAQTKGWY \\
\hline$y_{1}^{+1}$ & 182.08121 & 182.06237 & 103.5 & $\bar{Y}$ \\
\hline$y_{2}{ }^{+1}$ & 368.16053 & 368.16082 & 0.8 & WY \\
\hline$y_{4}{ }^{+1}$ & 553.27695 & 553.27671 & 0.4 & KGWY \\
\hline
\end{tabular}




\begin{tabular}{|l|l|l|l|l|}
\hline $\mathbf{y}_{14}{ }^{+2}-\mathbf{2 H}$ & 777.877765 & 777.87447 & 4.2 & GCGTKRTAQTKGWY \\
\hline $\mathbf{y}_{15}{ }^{+1} \mathbf{- 2 H}$ & 1641.78024 & 1641.76671 & 8.2 & SGCGTKRTAQTKGWY \\
\hline
\end{tabular}

F. Q31G-TqqA

\begin{tabular}{|c|c|c|c|c|}
\hline Ion & Calc $\mathrm{m} / \mathrm{z}$ & Obs $\mathrm{m} / \mathrm{z}$ & $\Delta p p m$ & Sequence \\
\hline$b_{2}^{+1}$ & 215.13906 & 215.12682 & 56.9 & TL \\
\hline$b_{9}^{+1}$ & 904.46696 & 904.45019 & 4.2 & TLSGCGTKR \\
\hline$b_{14}{ }^{+2}-2 \mathrm{H}$ & 709.364495 & 709.36222 & 3.2 & TLSGCGTKRTGQTK \\
\hline$b_{15}+2-2 H$ & 737.875225 & 737.86978 & 7.4 & TLSGCGTKRTGQTKG \\
\hline$b_{16}+2-2 H$ & 830.914885 & 830.91549 & 0.7 & TLSGCGTKRTGQTKGW \\
\hline$b_{17}+2-2 H$ & 912.446545 & 912.44596 & 0.6 & TLSGCGTKRTGQTKGWY \\
\hline $\mathrm{y}_{1}^{+1}$ & 182.08121 & 182.06292 & 100.4 & $\bar{Y}$ \\
\hline $\mathrm{y}_{2}^{+1}$ & 368.16053 & 368.167012 & 17.6 & WY \\
\hline $\mathrm{y}_{15}{ }^{+2}-2 \mathrm{H}$ & 814.385955 & 814.382544 & 4.2 & SGCGTKRTGQTKGWY \\
\hline
\end{tabular}


Table S9. Prevalence of TqqB. A BLAST analysis was carried out with TqqB. Several hits were identified with significant \% identity to TqqB. The genomic context of each of was analyzed and several gene clusters were identified that contained both an $A B C$ transporter and a precursor peptide with homology to TqqA.

\begin{tabular}{|c|c|c|c|}
\hline Strain & $\begin{array}{c}\text { NCBI } \\
\text { Protein ID }\end{array}$ & $\begin{array}{c}\text { \% ID to } \\
\text { TqqB }\end{array}$ & Precursor Sequence \\
\hline $\begin{array}{c}\text { Streptococcus } \\
\text { azizii }\end{array}$ & ONK263421 & $58 \%$ & $\begin{array}{c}\text { MVKMNLKNLSSKLLKIKSMPLSGCGTKRTQ } \\
\text { QTKGNLA }\end{array}$ \\
\hline $\begin{array}{c}\text { Atopobacter sp. } \\
\text { AH10 }\end{array}$ & $\begin{array}{c}\text { WP_121565 } \\
910.1\end{array}$ & $43 \%$ & $\begin{array}{c}\text { MKQLSLYDLKAKLTIETGQSIRNCGTKRTKN } \\
\text { TKLISF }\end{array}$ \\
\hline $\begin{array}{c}\text { Nosocomiicoccus } \\
\text { massiliensis strain } \\
\text { UMB0959 }\end{array}$ & $\begin{array}{c}\text { WP_102167 } \\
102.1\end{array}$ & $37 \%$ & $\begin{array}{c}\text { MSKKEFLKGLAERQSVKALGCGTSKTKNTK } \\
\text { GPIPI }\end{array}$ \\
\hline $\begin{array}{c}\text { Anaerosalibacter } \\
\text { massiliensis }\end{array}$ & $\begin{array}{c}\text { WP_042679 } \\
969.1\end{array}$ & $32 \%$ & $\begin{array}{c}\text { MNKTNFFNYKASKITPKAKYCGPTVITICPDL } \\
\text { VLSAARPKK }\end{array}$ \\
\hline $\begin{array}{c}\text { Bacillus cereus } \\
\text { strain B4080 }\end{array}$ & $\begin{array}{c}\text { WP_046945 } \\
647.1\end{array}$ & $31 \%$ & $\begin{array}{c}\text { MNSNEFLALEDLLSRSVDTLKRCGTRKTK } \\
\text { RTS }\end{array}$ \\
\hline $\begin{array}{c}\text { Marinitoga } \\
\text { hydrogenitolerans } \\
\text { DSM 16785 }\end{array}$ & $\begin{array}{c}\text { WP_072866 } \\
099.1\end{array}$ & $29 \%$ & MKNIKKFLKVVVYGGGCGTKRTKNTGSFTL \\
\hline
\end{tabular}

Figure S1: UV-Vis spectrum of purified and reconstituted TqqB. The absorption band at $\sim 620 \mathrm{~nm}$ is most likely due to a contaminating protein, which we identified by in-gel digestion and mass spectrometry of the resulting fragments as Yqjl. ${ }^{3}$ This protein has been shown to bind $\mathrm{Ni}^{2+}$ and $\mathrm{Fe}^{2+}$, which give the broad absorption feature at $\sim 620 \mathrm{~nm}$ (after oxidation to $\mathrm{Fe}^{3+}$ in the case of iron), though at this point we cannot rule out that the feature is due to one or more auxiliary $2 \mathrm{Fe}-2 \mathrm{~S}$ clusters. ${ }^{2,3}$

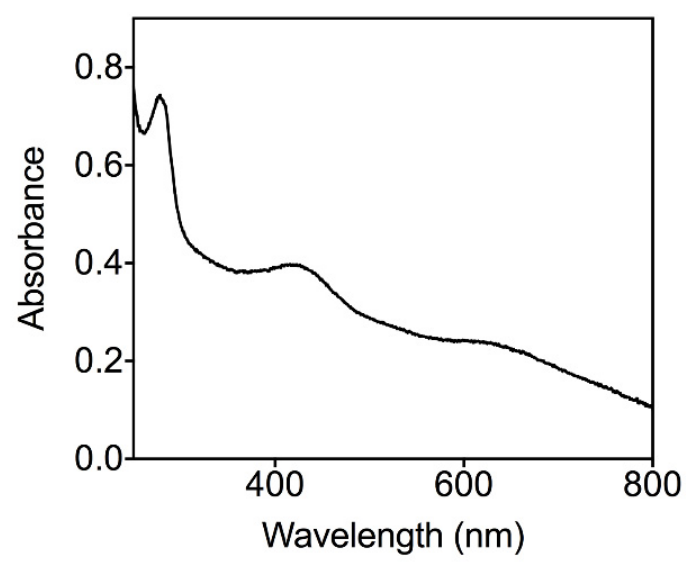


Figure S2: Alignment of C-terminal domains in TqqB and SuiB. ${ }^{4}$ The Cys residues involved in ligation of Auxl and Auxll in SuiB are shown in red and blue, respectively. Residues proposed to be involved in ligation of the Aux cluster in TqqB are shown in red. All Cys residues in this domain are conserved between the 270 members of the TQQ subfamily. This alignment shows that TqqB has four Cys residues in its Twitch domain that could provide four ligands to the Aux cluster. However, crystallographic and/or spectroscopic studies are required to determine if all four available Cys ligands coordinate the Aux cluster or if there is an open coordination site for substrate binding, as depicted in our first mechanistic proposal.

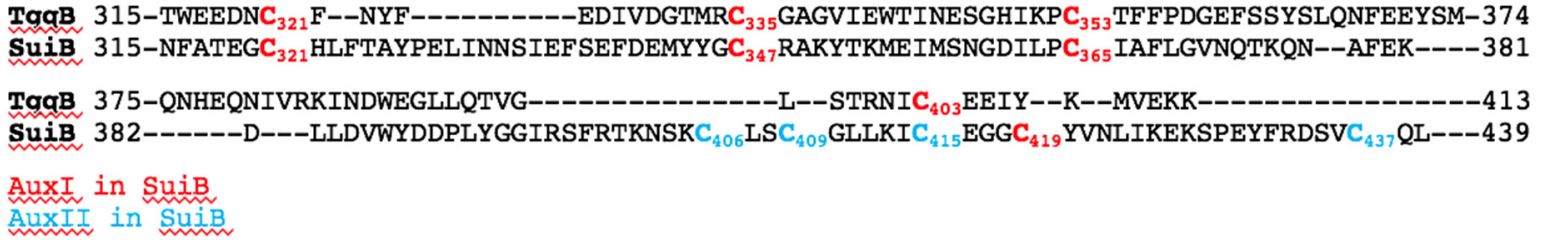

Figure S3. Time-dependent formation of 5'-dA in the reaction of TqqB with SAM and sodium dithionite in the absence of substrate. Quantification was carried out by integration of the area under the 5'-dA peak for a single replicate at each timepoint and comparison to a standard curve made in duplicate from an authentic standard.

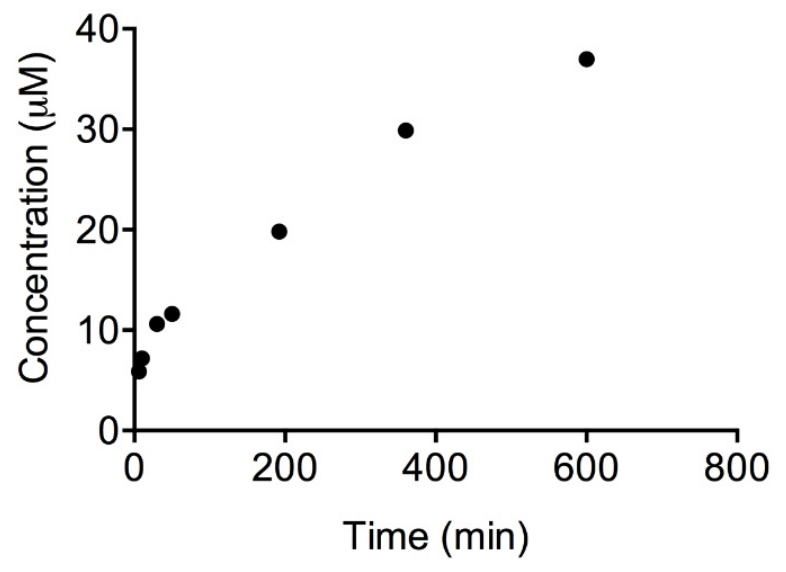


Figure S4. Time-dependent formation of product and 5'-dA in the presence of substrate from a single replicate at each timepoint. Shown is the integrated area of the extracted ion peak for the -2 Da product mass or 5 '-dA as a function of time.

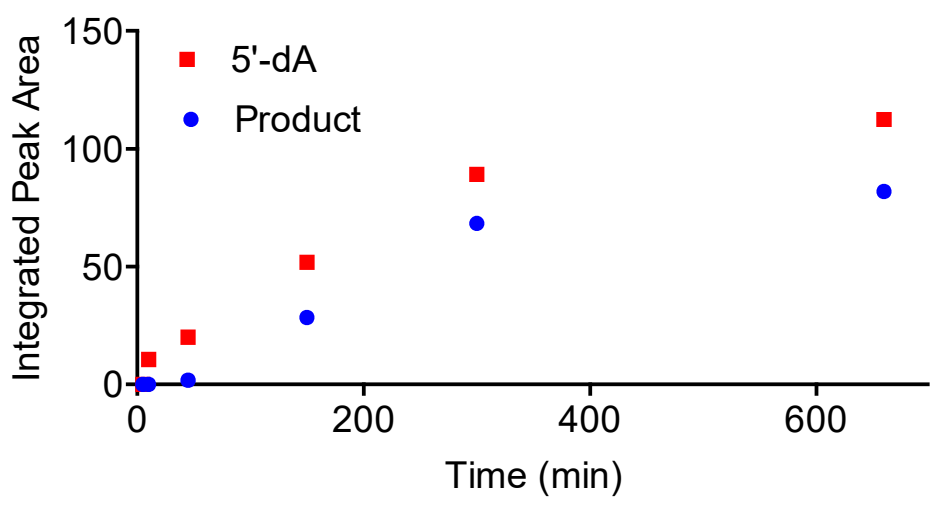

Figure S5. Enzymatic activity of TqqB active site cluster (C112A/C119A) and auxiliary cluster (C335A/C353A) mutants. Shown is the extracted ion count for the -2 Da product mass for each reaction.

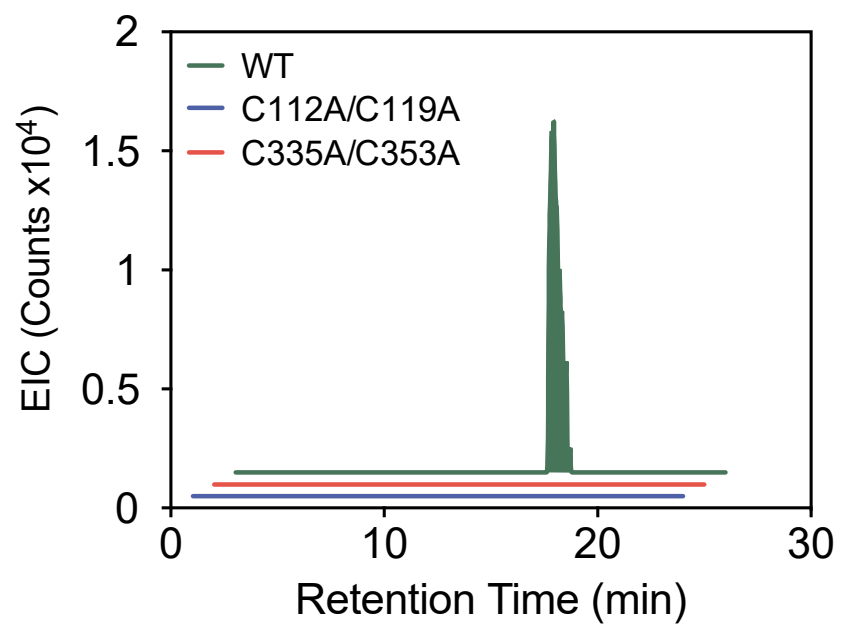


Figure S6. TOCSY slice (in $\mathrm{H}_{2} \mathrm{O}_{/} \mathrm{D}_{2} \mathrm{O}$ ) for the substrate-T33 methyl group (A), productT33 methyl group (B), substrate-K34 $\varepsilon^{-1} \mathrm{Hs}(\mathrm{C})$, product-K34 $\varepsilon^{-1} \mathrm{Hs}(\mathrm{D})$. No significant changes are observed between the substrate and product spectra for these residues.

A

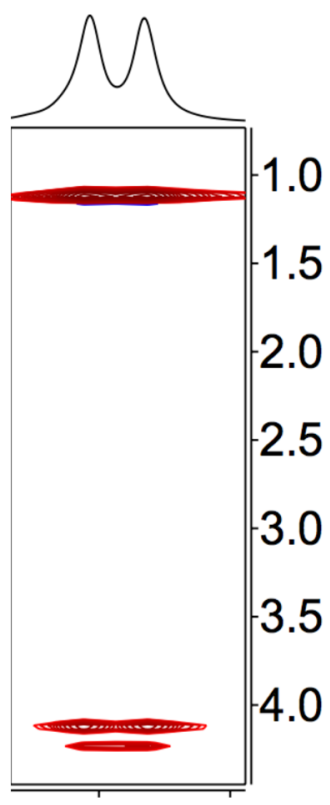

1.121 .10
B

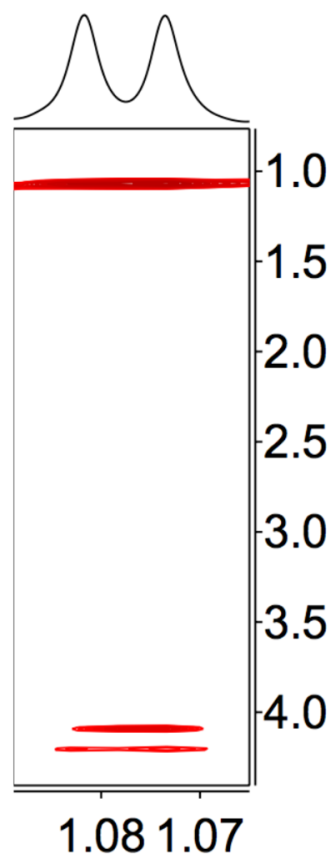

C

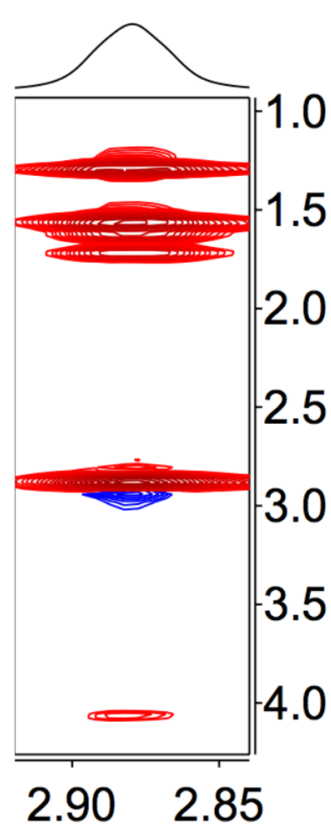

D

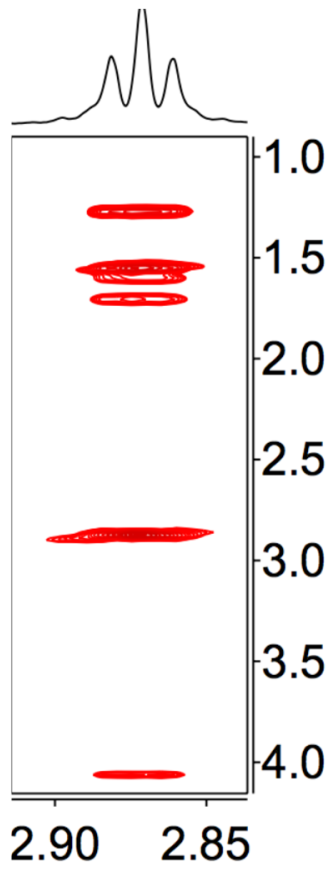

Figure S7. NMR spectra of the TqqA substrate in $\mathrm{D}_{2} \mathrm{O}$ (pages $\mathrm{S} 18-\mathrm{S} 20$ ).
A. ${ }^{1} \mathrm{H}$ spectrum

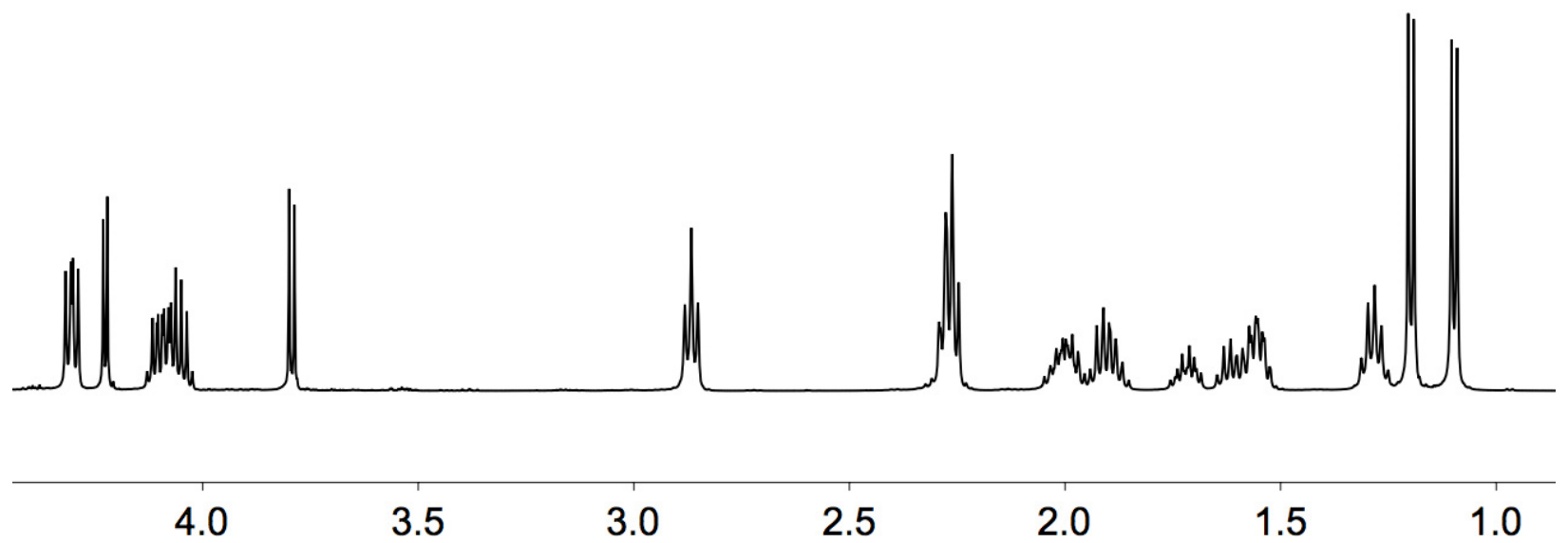


B. COSY spectrum

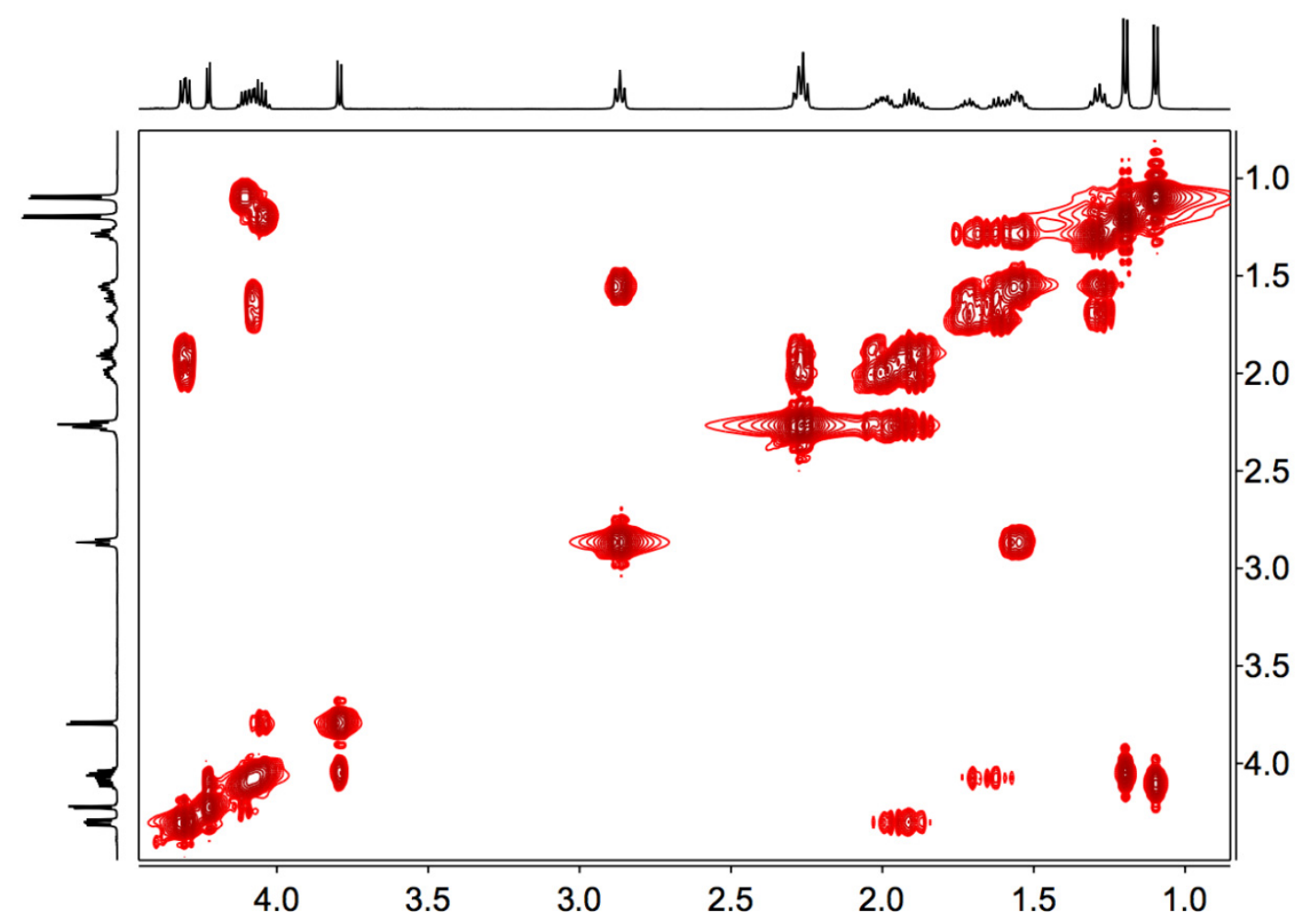

C. HSQC spectrum

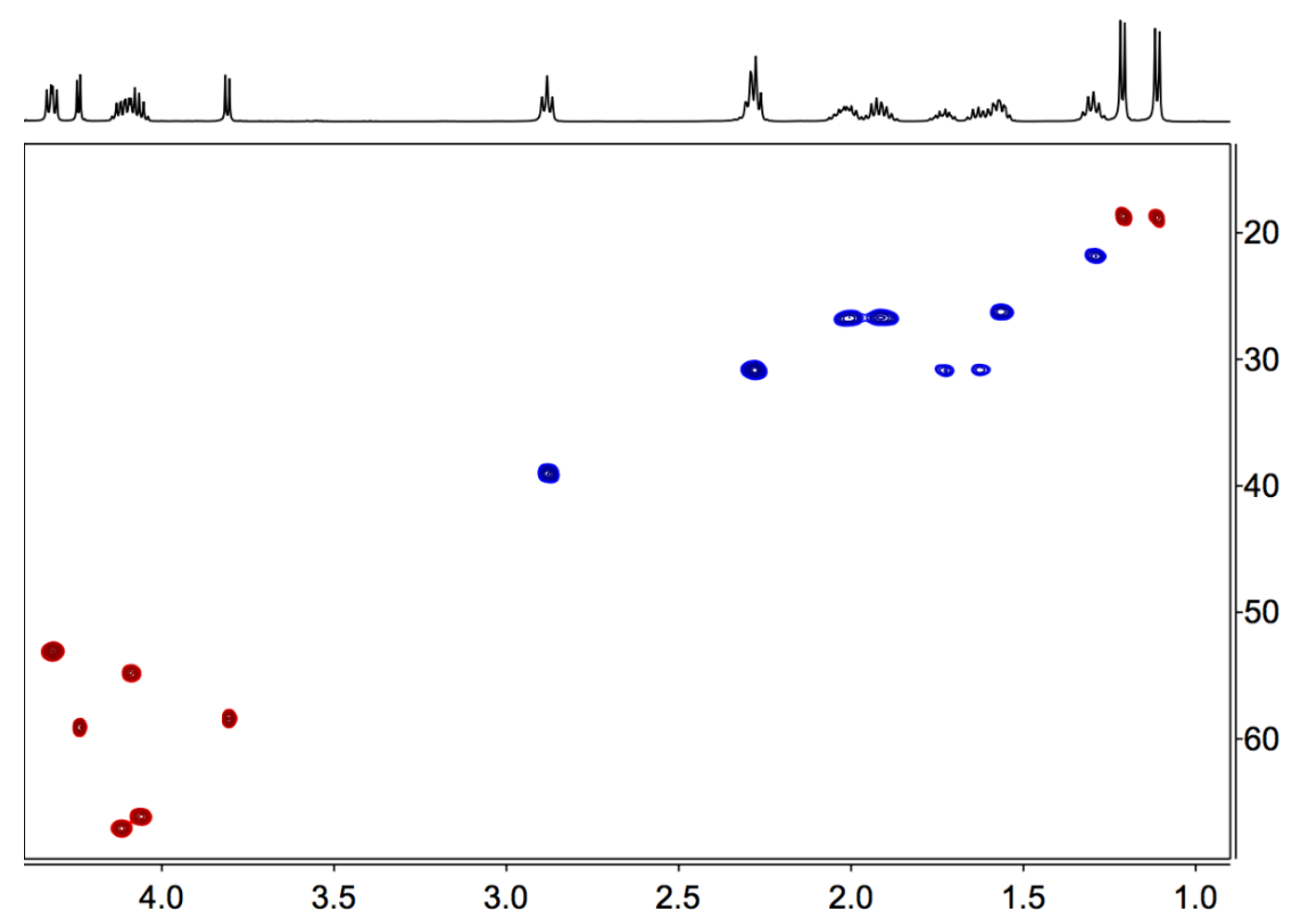


D. HMBC spectrum

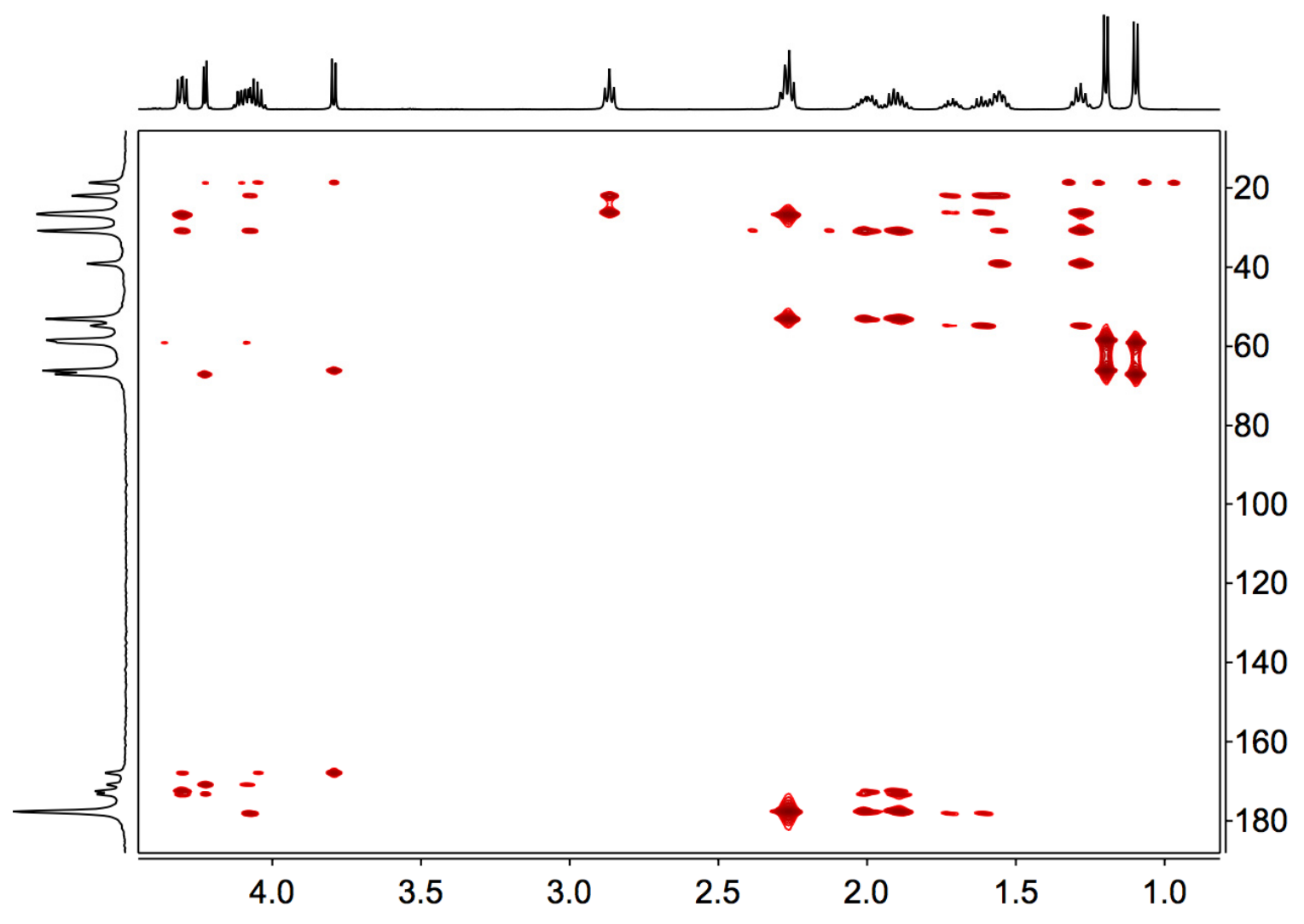

Figure S8. NMR spectra for the purified, cut product of TqqB in $\mathrm{D}_{2} \mathrm{O}$ (pages $\mathrm{S} 20-\mathrm{S} 22$ ).

A. ${ }^{1} \mathrm{H}$ spectrum

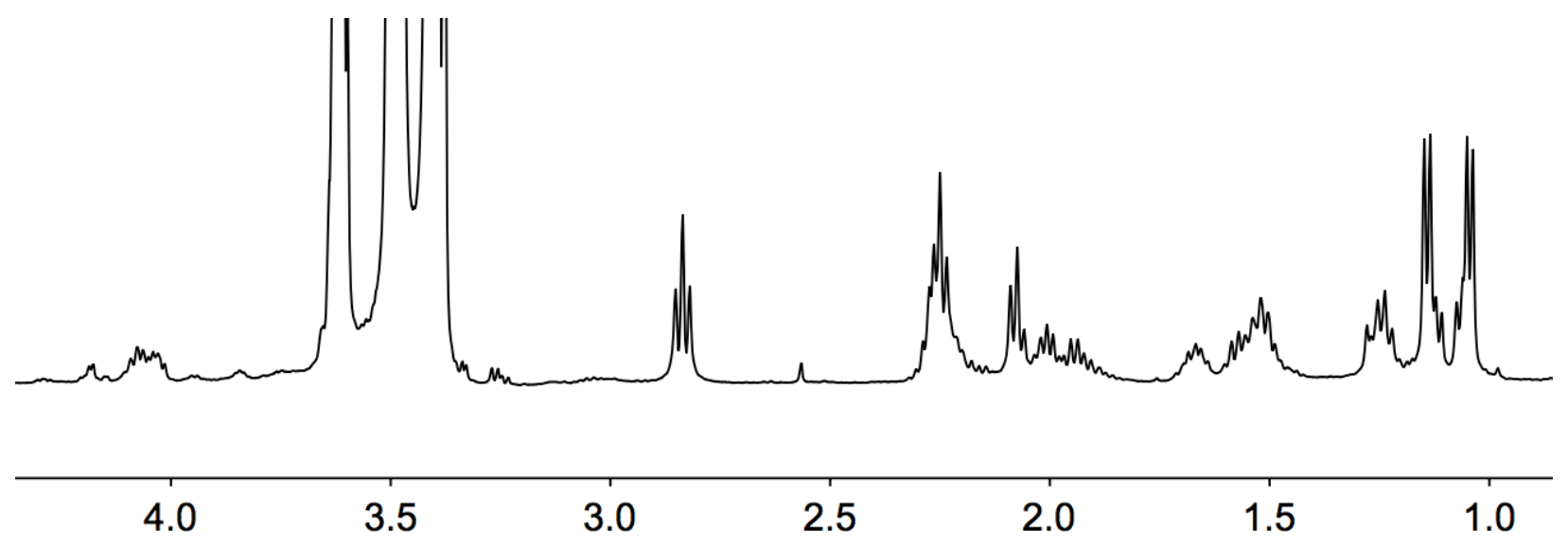


B. COSY spectrum

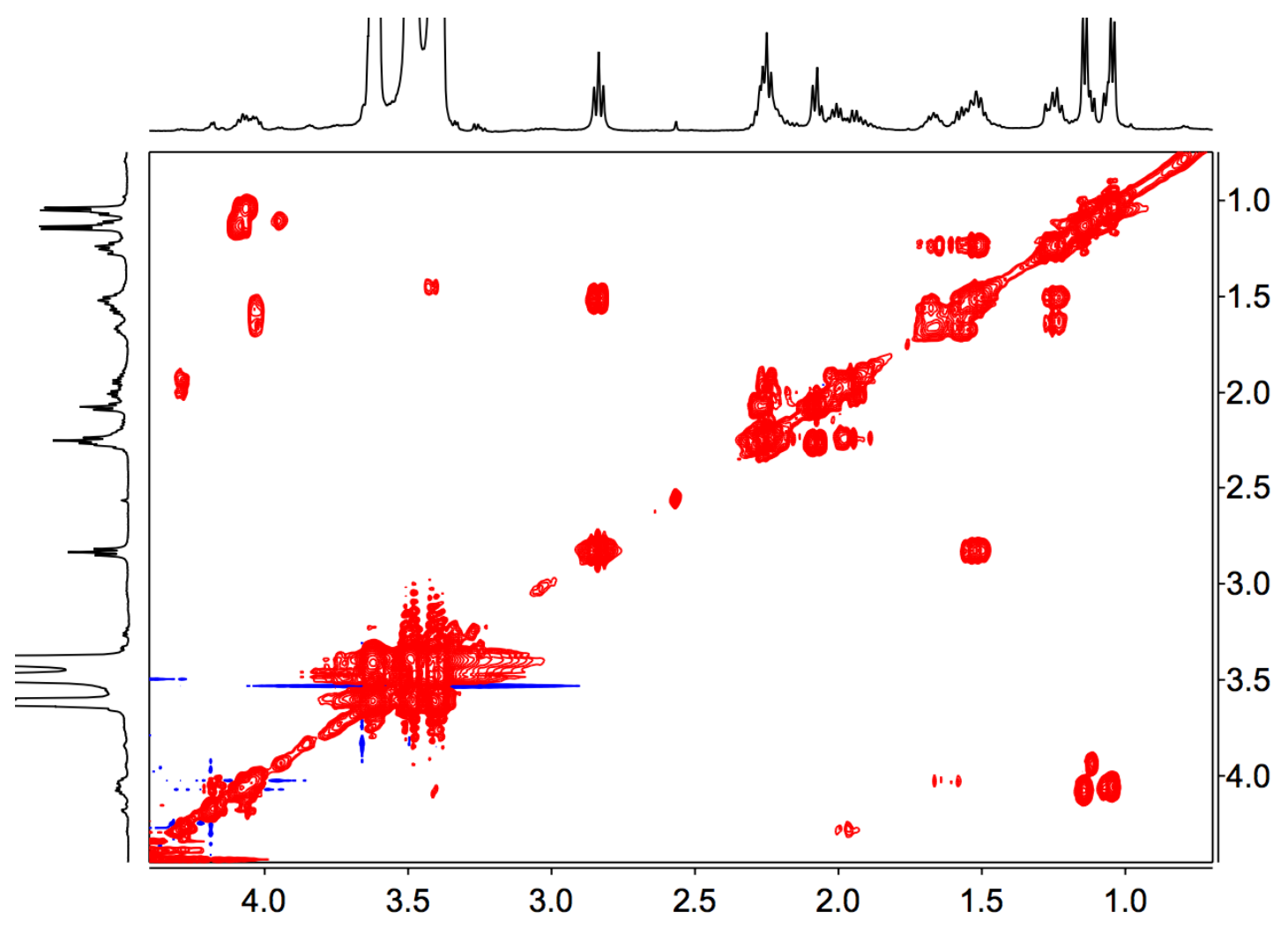

\section{TOCSY spectrum}

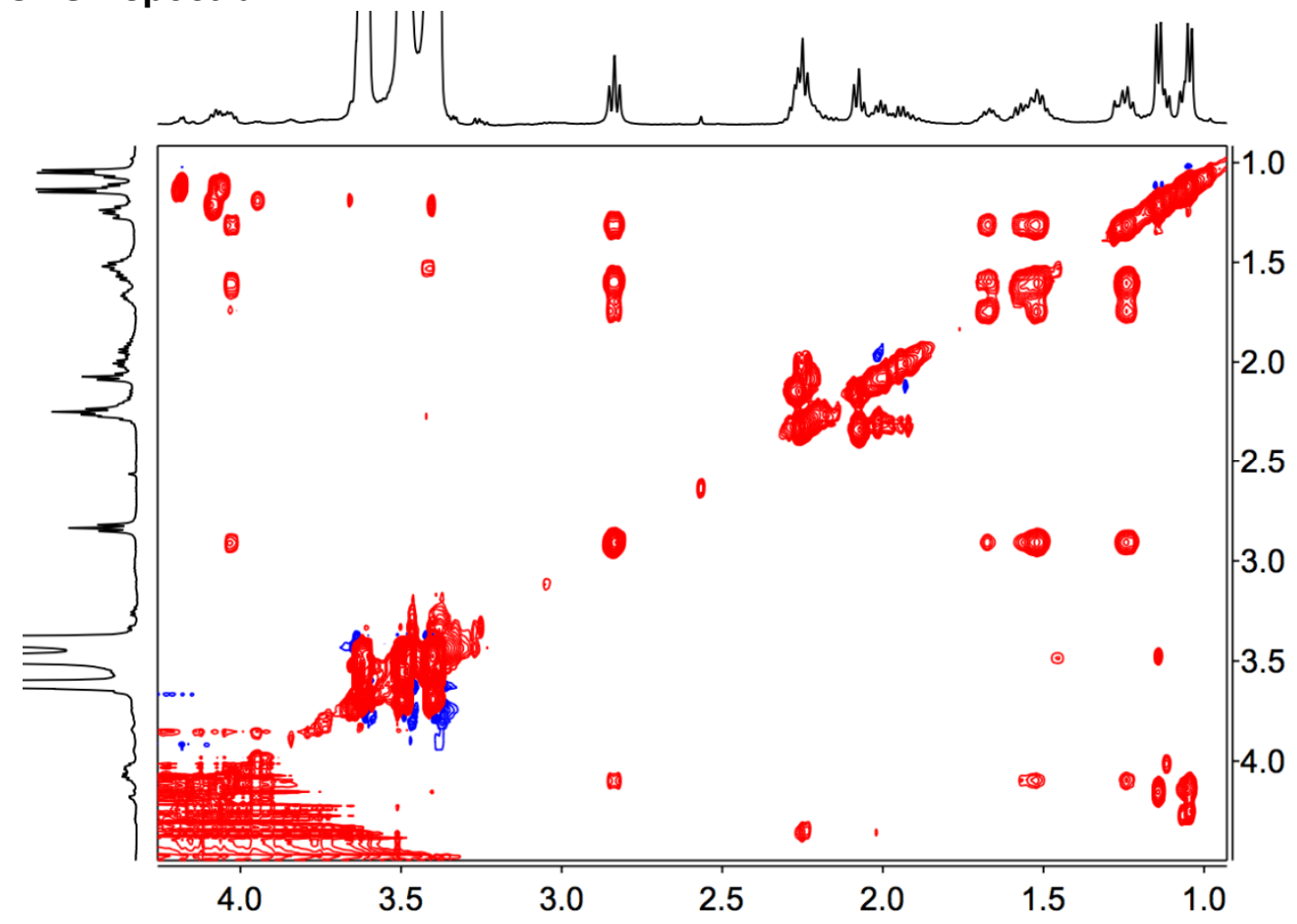




\section{HSQC spectrum}

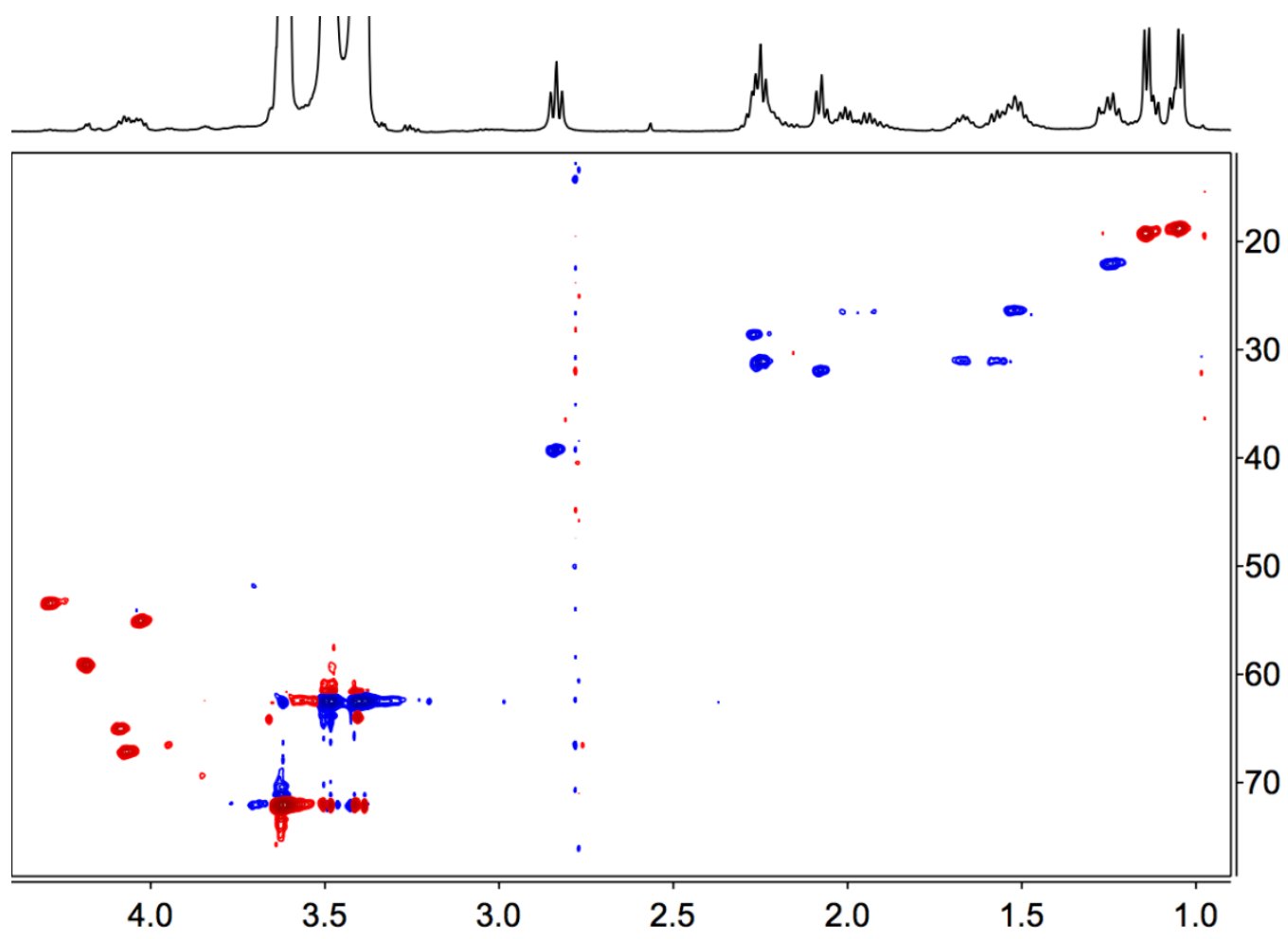

\section{E. HMBC spectrum}

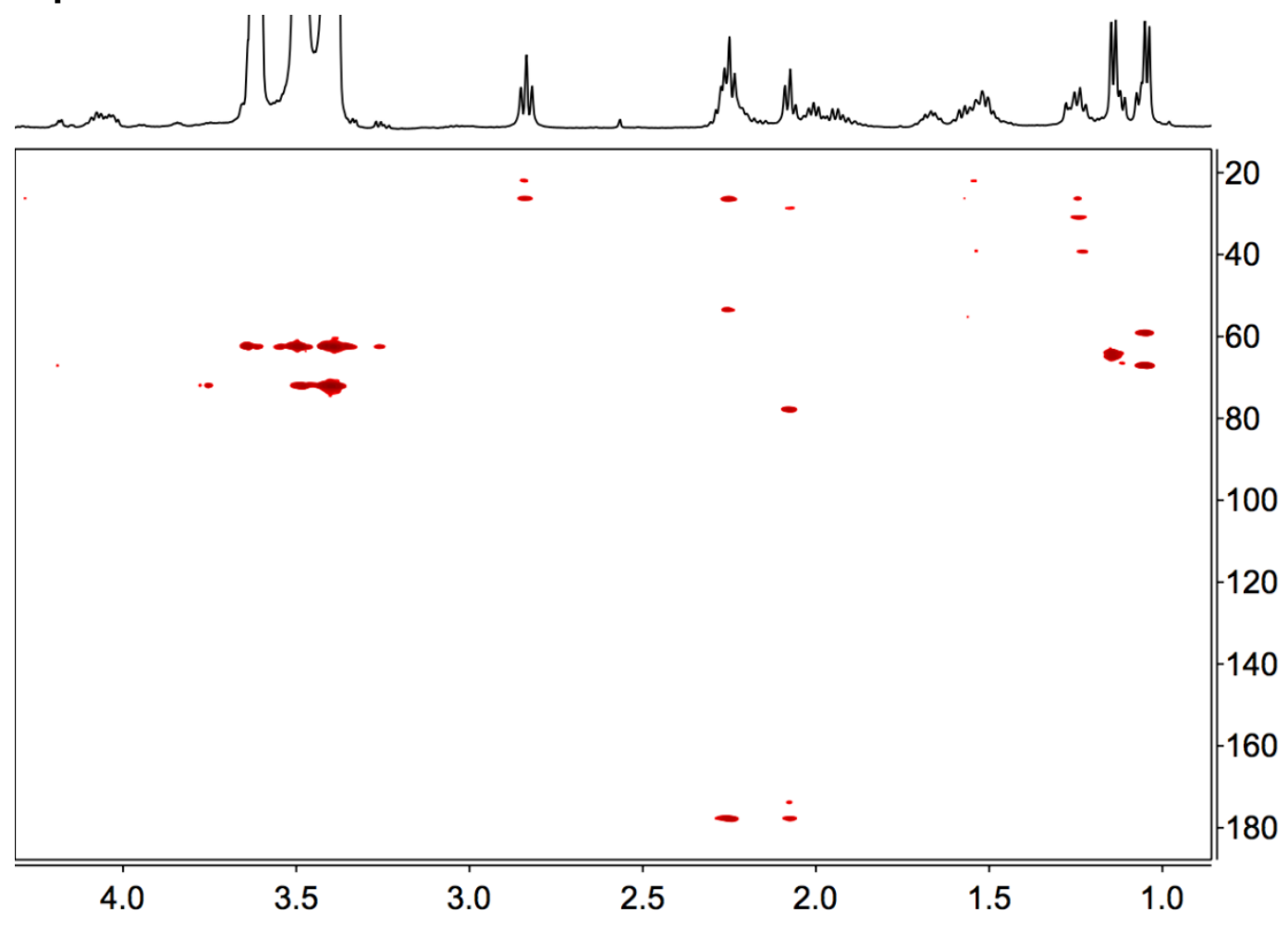


Figure S9. NMR spectra of TqqA in $\mathrm{H}_{2} \mathrm{O} / \mathrm{D}_{2} \mathrm{O}\left(19: 1\right.$, pages S23-S24) at $4^{\circ} \mathrm{C}$.

A. ${ }^{1} \mathrm{H}$ spectrum

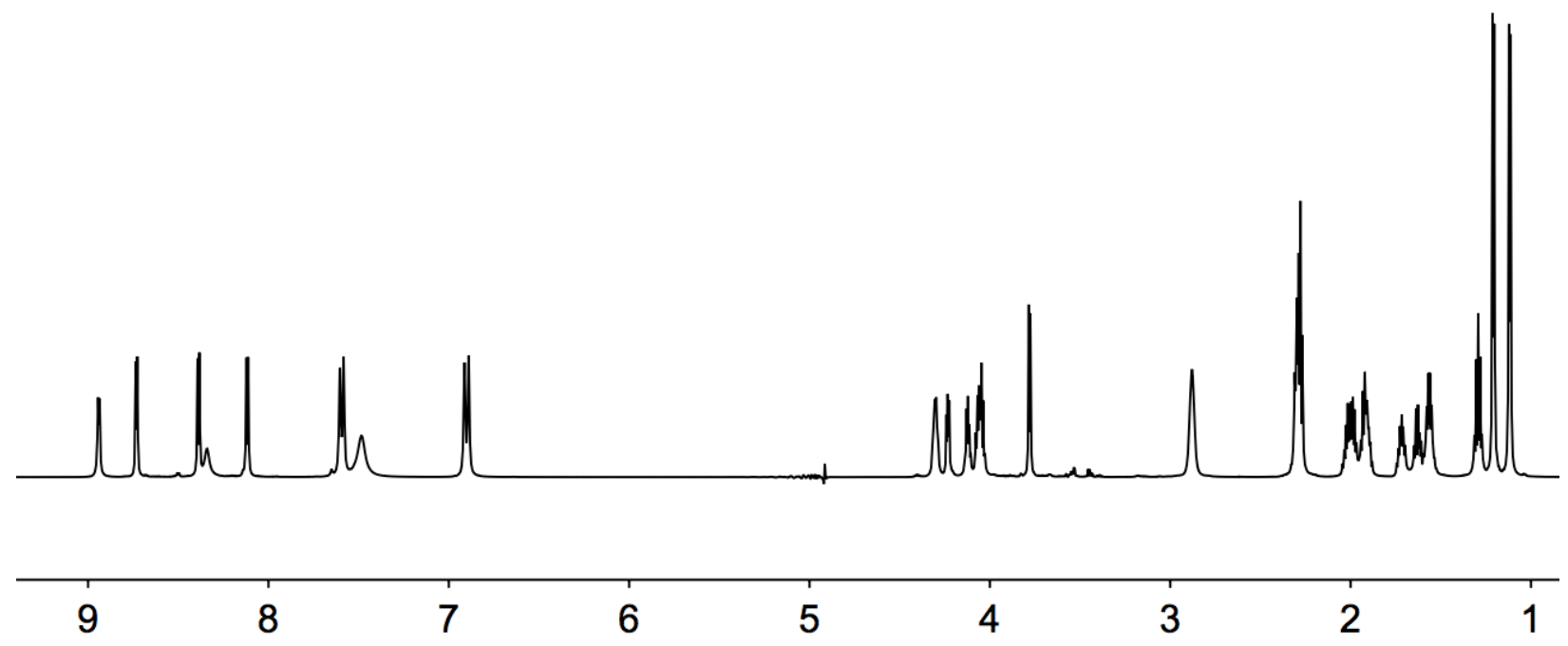

B. TOCSY spectrum

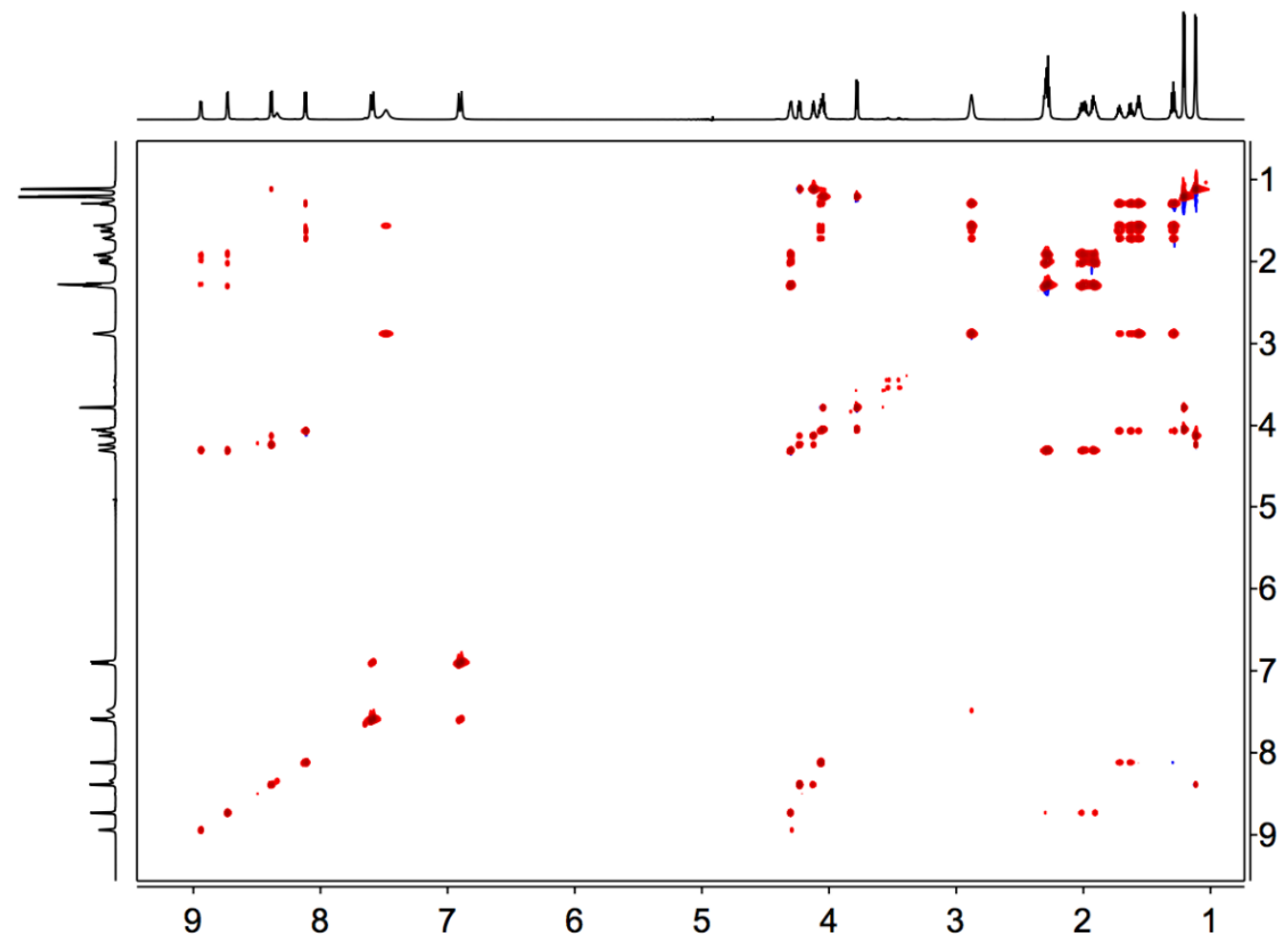


C. ROESY spectrum

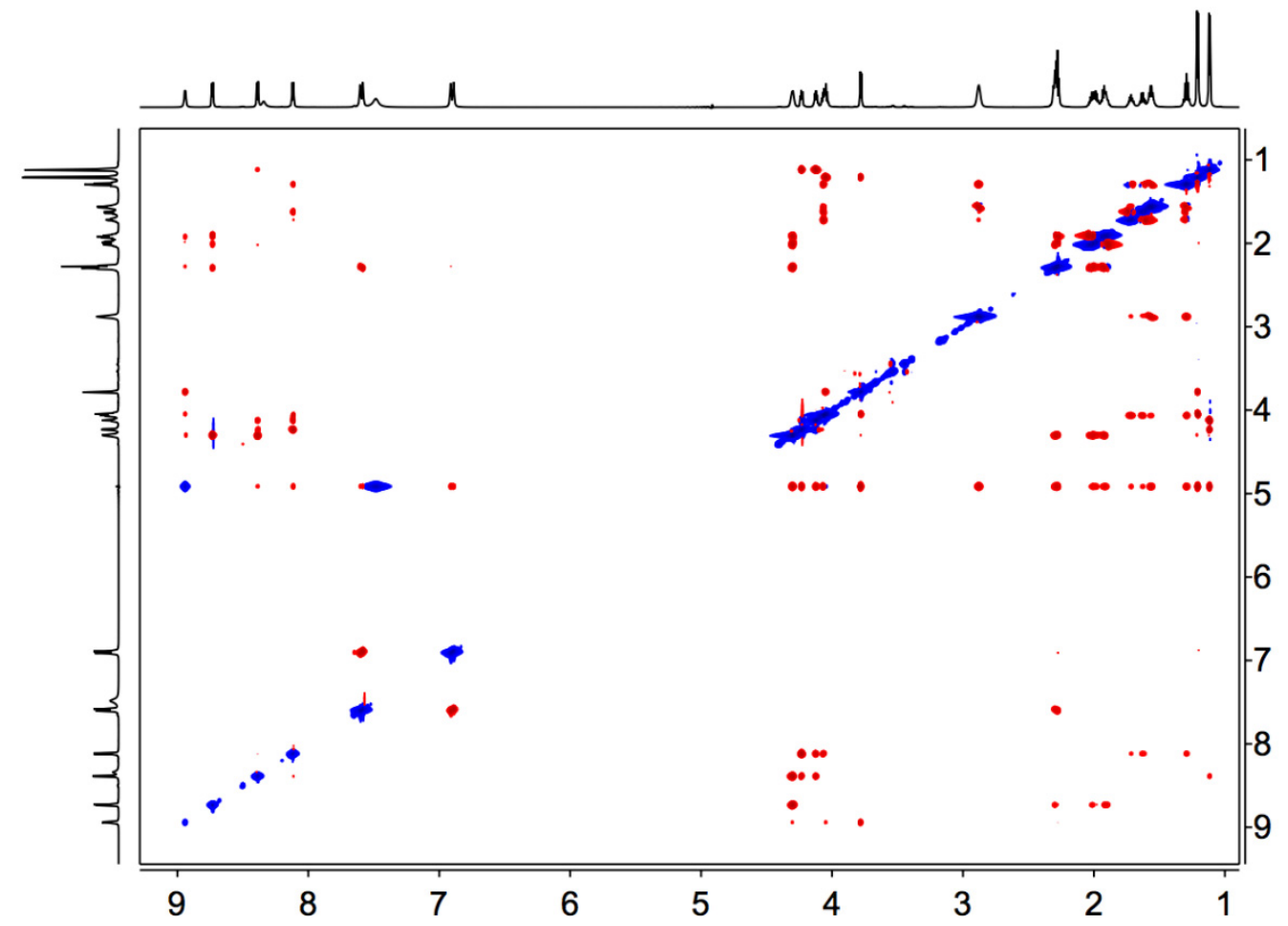

Figure S10. NMR spectra of the purified, cut TqqB product in $\mathrm{H}_{2} \mathrm{O}_{/} \mathrm{D}_{2} \mathrm{O}(19: 1)$ at $4^{\circ} \mathrm{C}$ (pages S24-S27).

\section{A. ${ }^{1} \mathrm{H}$ spectrum}

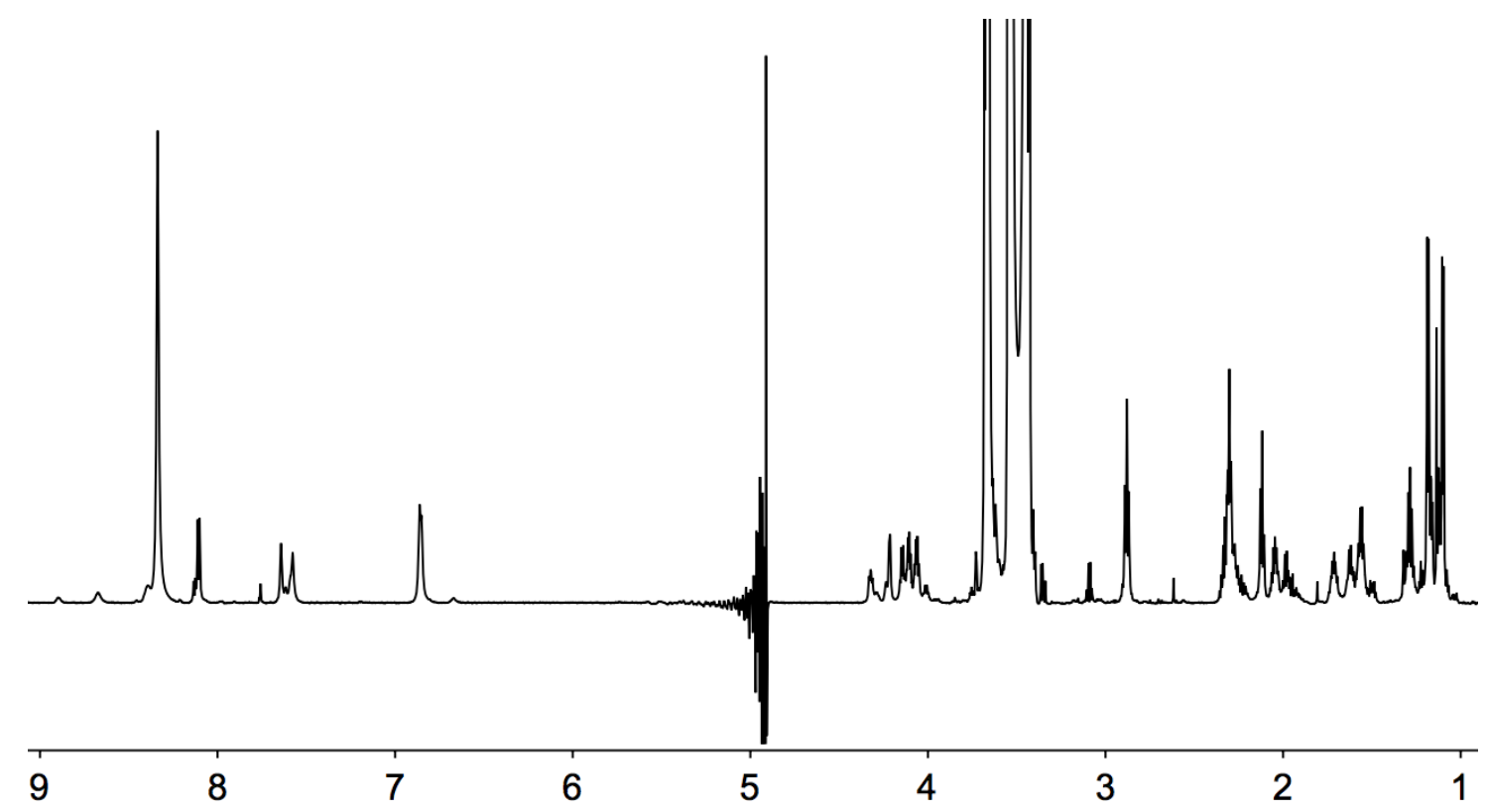




\section{B. TOCSY spectra}
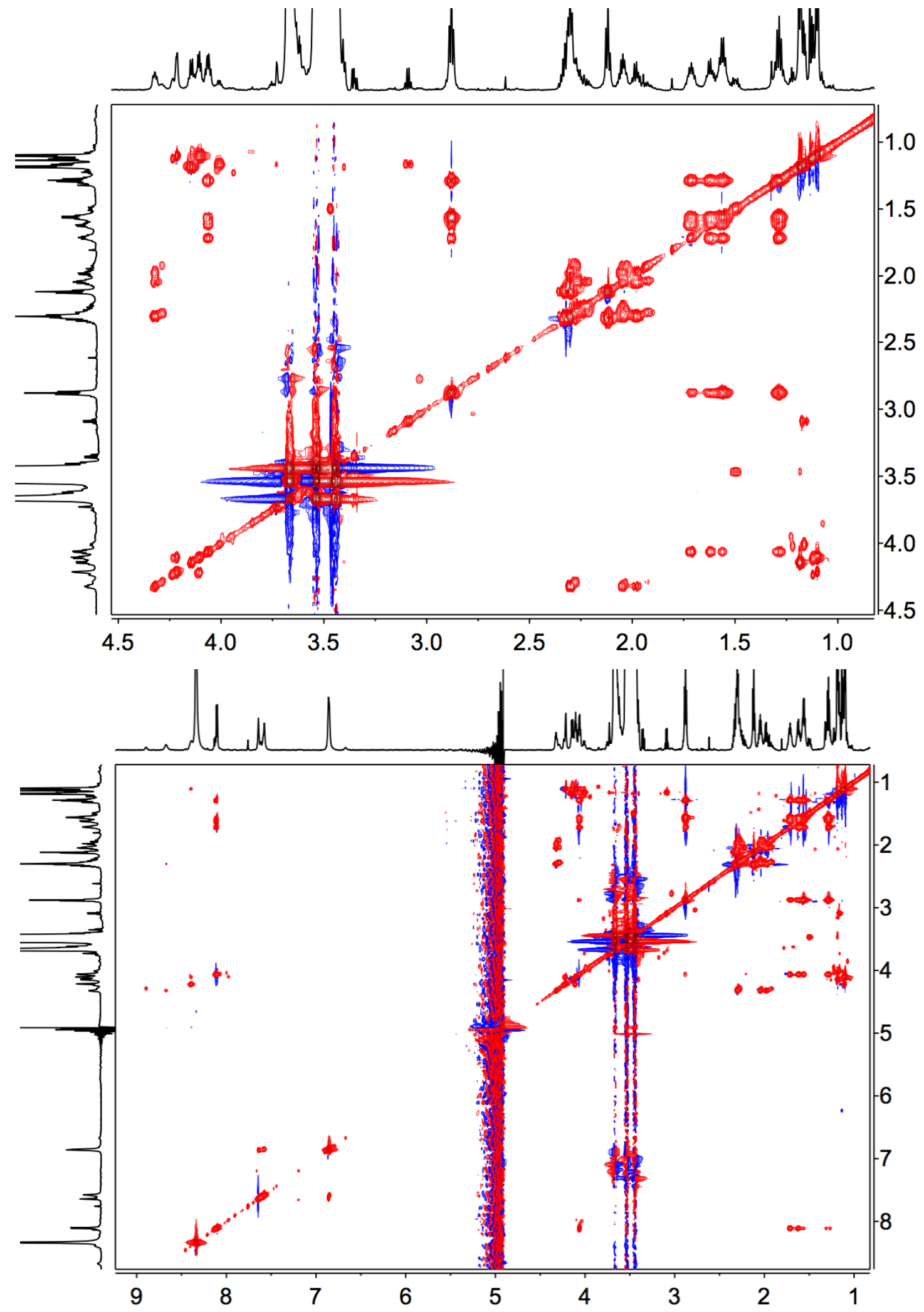


\section{ROESY spectra}
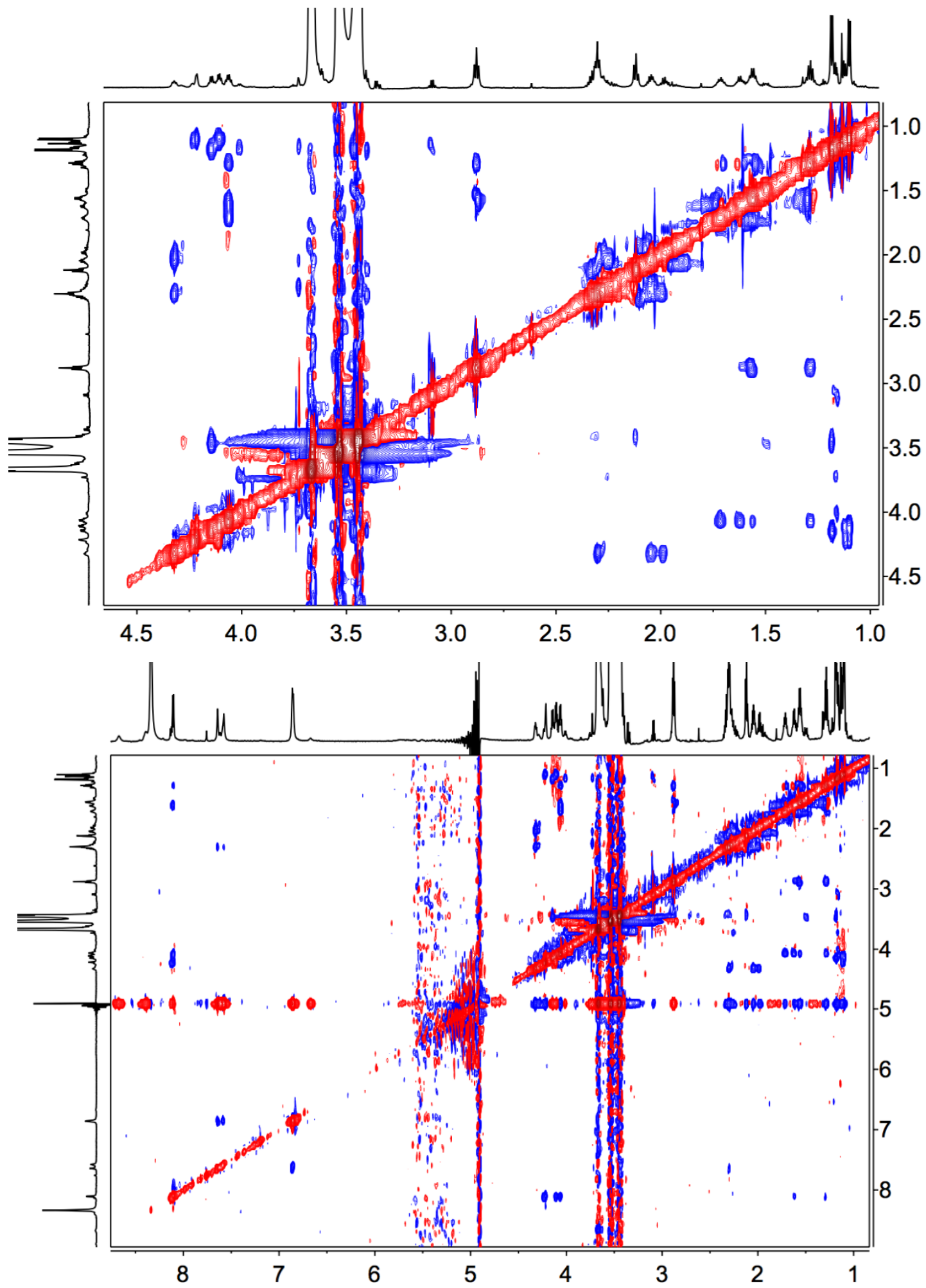


\section{HSQC spectrum}

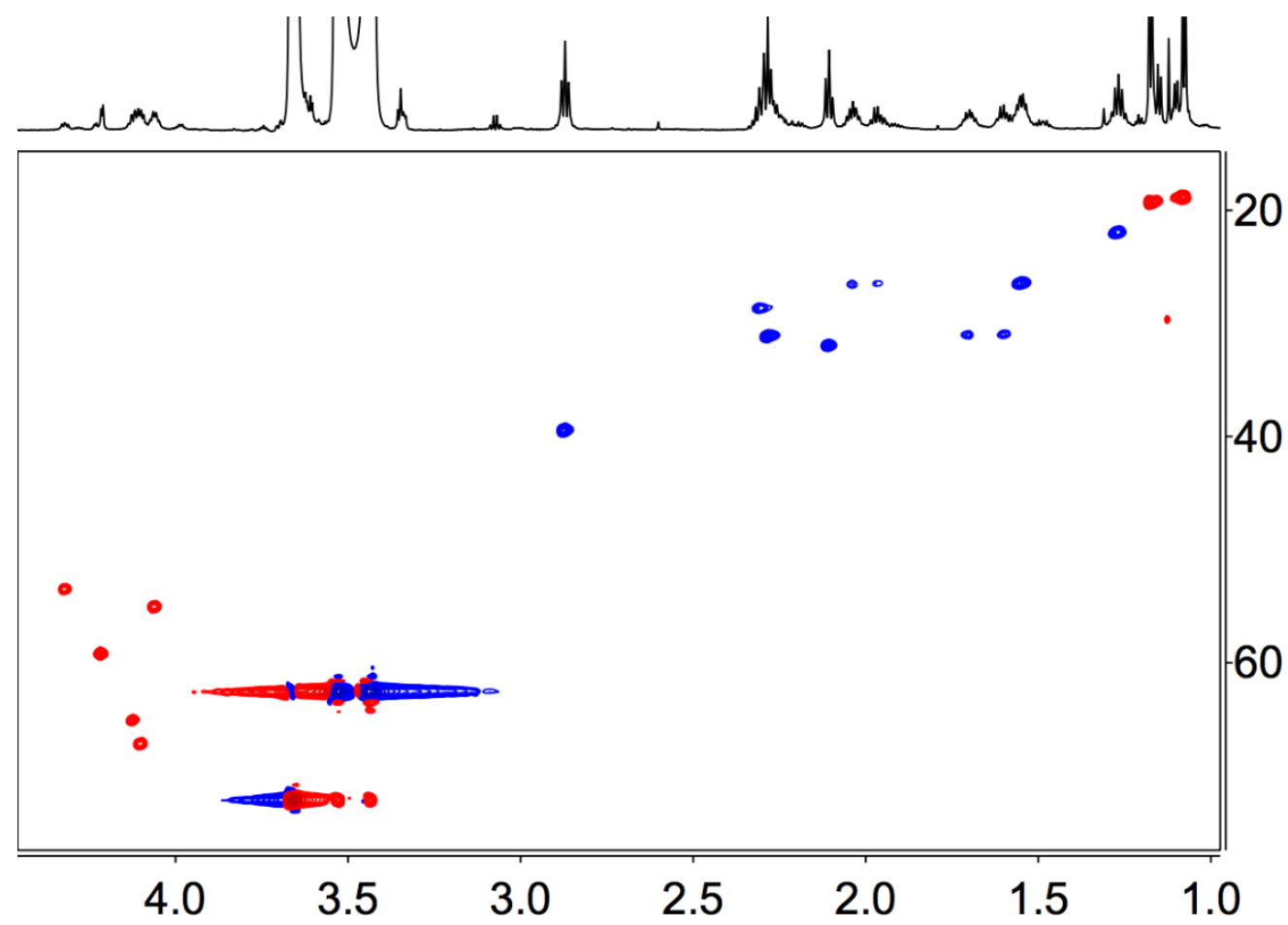

Figure S11. Logo plot of TqqA homologs. The precursor peptides from gene clusters homologous to the TQQ cluster (shown in Table S8) were aligned and a logo plot was generated. ${ }^{5}$ The Thr residue involved in ether bond formation is strictly conserved along with a CG motif that may be the site of proteolysis to generate the mature peptide.
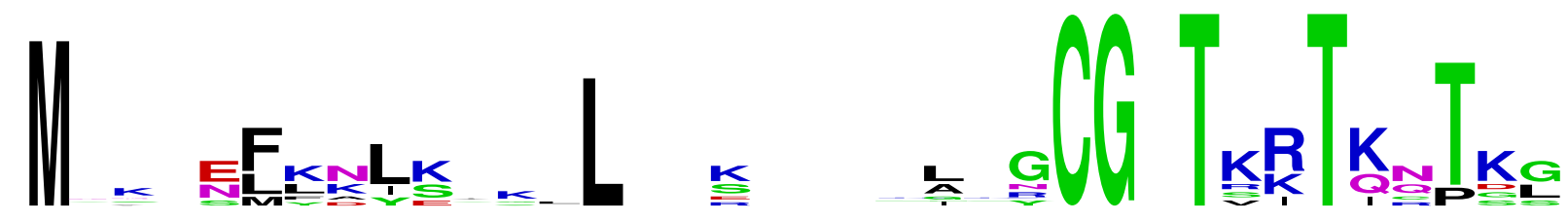


\section{Supplementary References}

1. Bushin, L. B.; Seyedsayamdost, M. R. Guidelines for determining the structures of radical SAM enzyme-catalyzed modifications in the biosynthesis of RiPP natural products. Methods Enzymol. 2018, 606, 439-460.

2. Barr, I.; Latham, J. A.; lavarone, A. T.; Chantarojsiri, T.; Hwang, J. D.; Klinman, J. P. Demonstration that the radical S-adenosylmethionine (SAM) enzyme PqqE catalyzes de novo carbon-carbon cross-linking within a peptide substrate PqqA in the presence of the peptide chaperone PqqD. J. Biol. Chem. 2016, 291, 8877-8884.

3. Wang, S.; Wu, Y.; Outten, F. W. Fur and the novel regulator Yqjl control transcription of the ferric reductase gene yqjH in Escherichia coli. J. Bacteriol. 2011, 193, 563-574.

4. Davis, K. M.; Schramma, K. R.; Hansen, W. A.; Bacik, J. P.; Khare, S. D.; Seyedsayamdost, M. R.; Ando, N. Structures of the peptide-modifying radical SAM enzyme SuiB elucidate the basis of substrate recognition. Proc. Natl. Acad. Sci. USA 2017, 114, 10420-10425.

5. Crooks, G. E.; Hon, G.; Chandonia, J.-M.; Brenner, S. E. WebLogo: a sequence logo generator. Genome Res. 2004, 14, 1188-1190. 